\title{
LA 'GUERRA DE LAS TERRAZAS': PRIVATIZACIÓN DEL ESPACIO PÚBLICO POR EL TURISMO EN SEVILLA Y BARCELONA
}

\author{
Berezi Elorrieta Sanz* \\ Universitat de Barcelona \\ Centro Universitario Internacional de Barcelona \\ https://orcid.org/0000-0002-7473-2314 \\ Miguel García Martín** \\ Universidad de Sevilla \\ https://orcid.org/0000-0002-3318-4884 \\ Aurélie Cerdan Schwitzguébel*** \\ Escuela Universitaria de Hotelería y Turismo. Universitat de Barcelona \\ https://orcid.org/0000-0003-3346-2140 \\ Anna Torres-Delgado**** \\ Universitat de Barcelona \\ https://orcid.org/0000-0001-8655-1556
}

\section{RESUMEN}

La ocupación del espacio público para usos privados está generando crecientes conflictos en algunos destinos turísticos urbanos, donde las terrazas se han convertido en motivo de controversia. El objetivo de esta investigación es analizar, de forma comparada, el marco regulador y la ocupación efectiva del espacio público por parte de las terrazas de veladores en zonas turísticas de Sevilla y Barcelona. Una combinación de análisis de contenido y trabajo de campo arroja unos resultados que muestran las limitaciones de las ordenanzas para

Fecha de recepción: 28 de octubre de 2019

Fecha de aceptación: 11 de junio de 2020

* Universitat de Barcelona. C/ Montalegre, 6. 08001 BARCELONA (España).

Centro Universitario Internacional de Barcelona. Av. Josep Tarradellas i Joan, 171. 08901 L'Hospitalet de Llobregat. BARCELONA (España). E-mail: berezielorrieta@gmail.com

** Universidad de Sevilla. C/ Doña María de Padilla s/n. 41004 SEVILLA (España). E- mail: mgmartin@ us.es

*** Escuela Universitaria de Hotelería y Turismo. Av. Can Marcet, 36-38. 08035 BARCELONA (España). E-mail: aurelie.cerdan@cett.cat

**** Universitat de Barcelona. C/ Montalegre, 6. 08001 BARCELONA (España). E-mail: annatorres@ ub.edu 
evitar una elevada ocupación del espacio público, más acentuada en entramados urbanos densos, pero contenida en las áreas que cuentan con una ordenación específica.

Palabras clave: Espacio público; terrazas de veladores; ocupación; privatización; turismo urbano.

\title{
The 'sidewalk cafe war': privatization of public space by tourism in Seville and Bar- celona
}

\begin{abstract}
The occupancy of public spaces for private purposes is causing increasing conflicts in several urban tourist destinations. Concretely, sidewalk cafes (which basically consist of tables and chairs) have become a matter of controversy. This research aims to compare both legal framework and factual occupancy concerning sidewalk cafes in urban tourist areas of two Spanish cities (Seville and Barcelona). Content analysis of the legal framework and fieldwork have been the main methods used. Results point to the limited capacity of city ordinances to restrain the increasing occupancy of public space. This phenomenon is more significant in the high-density areas of city centres but it is tempered in those areas where there is a specific regulation.
\end{abstract}

Keywords: public space; sidewalk cafes; occupancy; privatization; urban tourism.

\section{LAS TERRAZAS EN EL CENTRO DEL DEBATE}

La ocupación del espacio público para usos privados está generando crecientes conflictos en algunas ciudades españolas, especialmente aquellas que sufren una mayor afluencia turística, que padecen problemas de congestión, movilidad, ruido y otras molestias. En este contexto, las terrazas se han convertido en motivo de controversia en algunos centros urbanos, entre los que hallamos Sevilla y, especialmente, Barcelona. Agentes políticos, privados y sociales se encuentran inmersos en un debate sobre el difícil equilibrio entre la preservación del uso comunitario del espacio público, el descanso vecinal, y el ocio (tanto de turistas como de locales).

En el caso de Sevilla, la demanda turística en los últimos años ha sufrido un aumento espectacular: entre 2013 y 2017 el número de viajeros anuales pasa de los 2 a los 3 millones (Consorcio Turismo de Sevilla, 2018). Además, la afluencia de este volumen de turistas en la ciudad ha sido muy selectivo en términos espaciales, concentrándose en el casco histórico y en los barrios adyacentes (Jover y Díaz-Parra, 2020). La estrategia impulsada desde la administración local en la última década, consistente en consolidar el centro histórico como destino turístico pero apuntando, simultáneamente, a una extensión y desconcentración espacial, ha tenido un inevitable impacto en el espacio público y en el tejido comercial del distrito histórico, con la proliferación de restaurantes, bares y comercios ligados al sector turístico. Así, el debate sobre la regulación de las terrazas de 
veladores se ha convertido en un tema de interés general para la opinión pública, hasta el punto de conquistar las portadas de los principales medios de comunicación locales ${ }^{1}$.

En Barcelona, de forma similar, la irrupción de la polémica sobre la masificación turística ha avivado paralelamente el debate sobre el espacio público y, particularmente, sobre la presencia de terrazas, en una intensa pugna que los medios de comunicación llegaron a calificar como "guerra de las terrazas" (El Periódico, 2017). La reciente aprobación de una nueva normativa (Modificació de l'Ordenança de Terrasses) no ha estado exenta de controversia, puesto que significa una importante modificación respecto a la anterior, y su carácter más flexible es valorado negativamente por entidades vecinales y asociaciones de discapacitados, hasta el punto de llegar a interponer recursos judiciales ante el Tribunal Superior de Justicia de Cataluña (Blanchar, 2018). Los recursos contra esta nueva ordenanza denuncian el incumplimiento de normativas superiores sobre accesibilidad, sobre contaminación acústica y ambiental y sobre participación ciudadana. Asistimos, así, a la judicialización de un conflicto íntimamente relacionado con el llamado derecho a la ciudad (Lefebvre, 1969), donde algunos sectores denuncian la mercantilización del espacio público.

La presencia de terrazas no es, obviamente, la única causa de privatización del espacio público en los entornos urbanos; sin embargo, se trata de un factor muy relevante, tal y como llegó a señalar la propia Defensora del Pueblo de Barcelona, al reconocer que la cesión del espacio público al sector privado condiciona los usos del mismo y transforma las dinámicas que en él se desarrollan (Síndica de Greuges de Barcelona, 2015).Es por ello que este trabajo se centra en analizar la ocupación del espacio público por parte de las terrazas en dos ciudades donde, actualmente, existe un debate abierto al respecto.

\section{OBJETIVOS}

El objetivo general de esta investigación es analizar, de forma comparada, la ocupación del espacio público por parte de terrazas de veladores en zonas turísticas de Sevilla y Barcelona. De acuerdo a este planteamiento inicial, se formulan dos objetivos específicos: por un lado, analizar de forma comparada los marcos normativos municipales, con especial atención a los criterios regulatorios que determinan las áreas de ocupación y la distribución y número teórico de mesas. Y por otro lado, evaluar cuantitativamente la ocupación del espacio público por parte de las terrazas como fenómeno que contribuye a la privatización, en una muestra de zonas turísticas de Sevilla y Barcelona.

\section{MARCO TEÓRICO Y ESTADO DE LA CUESTIÓN}

El espacio público como concepto está estrechamente relacionado con el concepto de ciudad, con el que ha caminado de la mano a lo largo del proceso histórico de urbanización. Si bien afirmar que el espacio público es la ciudad puede resultar una concesión más poética que científica (Borja y Muxi, 2003; Borja, 2014), lo cierto es que sin espacio

1 No sin un tratamiento de la información algo sensacionalista. Pueden mencionarse, por poner algunos ejemplos, las portadas de Diario de Sevilla (14/10/2016; 21/10/2016; 18/04/2017) o ABC de Sevilla (17/12/2016; $02 / 03 / 2017$ ) 
público no hay ciudad (Benavides, 2016). Justamente porque, más allá de resultar de la separación física y formal entre la propiedad privada urbana (la edificación) y el dominio público, el espacio público tiene también un componente sociocultural, al ser allí donde los habitantes devienen ciudadanos (Borja, 2013). Tanto en su dimensión física, como en la política y la simbólica, es el lugar de las relaciones sociales, de la memoria colectiva y la identificación, del flujo, el contacto y el conflicto.

Precisamente por ello, el espacio público se resiente especialmente por las trasformaciones propias de la ciudad contemporánea. Estas dinámicas, a las que también contribuye el turismo, tienden a debilitar y privatizar el espacio público, en especial en los centros históricos de las ciudades monumentales. El debilitamiento, en tanto que una pérdida de calidad, se produce por la banalización formal y estética en calles y plazas, que hacen que los centros urbanos, más allá de sus singularidades unívocas, se parezcan cada vez más los unos a los otros (Muñoz, 2008; Beltrán, 2015; Cabrerizo, 2016). A su vez, la especialización económica y la pérdida de heterogeneidad social es fruto de la sustitución de unas actividades económicas y servicios públicos enfocados al residente por otros enfocados al visitante, cuando no del desplazamiento mismo de la población por la competencia de los apartamentos turísticos en el mercado inmobiliario (Cócola, 2016). Estos factores relacionados con la masificación turística han generado ya multitud de conflictos en diferentes ciudades de todo el mundo (Colomb y Novy, 2016; Milano y Mansilla, 2018). Todo ello deviene en una menor vitalidad y multifuncionalidad de actividades, usos y costumbres, propiciando la mercantilización de los barrios históricos (Kohn, 2004; Sorkin, 2004).

Por otro lado, el espacio público se privatiza. Es decir, se reduce o acota la extensión espacial de calles y plazas - privación espacial o de acceso - y se limita su condición de público - privación de actividad y uso- (García, 2011). Así sucede con el surgimiento de urbanizaciones cerradas (gated communities) y otras formas de cerramiento y limitación del acceso vinculadas a la cultura del miedo (Low, 2003; Juaristi, 2005; Glasze, Webster y Frantz, 2006; Cortés, 2010); o con la omnipresencia del coche como fundamento del modelo de movilidad individual y motorizada que, entre otras muchas consecuencias, substrae espacio público al ocupar hegemónicamente la vía pública para el tráfico rodado y el aparcamiento (Sheller y Urry, 2000; Rode et al., 2017; Rodríguez, 2017). También se produce una privación del espacio público con su concesión para actividades que, caso de las terrazas de veladores y otras instalaciones efímeras, implican un uso privativo, aunque temporal, del mismo.

Especialmente en este último caso, que es el que nos ocupa, se asiste a una confrontación simbólica entre el derecho de libre explotación comercial de una concesión administrativa legalmente obtenida por parte del empresario, de un lado, y el derecho de los ciudadanos al espacio público, de otro lado. Este último derecho forma parte de un más amplio derecho a la ciudad, un compromiso jurídico y ético de orden global por el que se debe garantizar que todos los habitantes de las ciudades gocen colectivamente de su riqueza, su cultura, sus bienes y su conocimiento (Capel, 2010; Correa, 2010). En esa línea, el espacio público constituye una de las condiciones básicas para la justicia urbana que, como factor de redistribución social, propicia un urbanismo vocacionalmente igualitario e integrador (Borja, 2004). Sin entrar a valorar las consecuencias jurídicas 
de las posibles contrariedades entre una libertad - la de ocupación para uso privativo del espacio público - y ese derecho al espacio público, en esta contribución se toman en consideración ambos supuestos, asumiendo que la normativa reguladora no logra apaciguar todas las posibles situaciones conflictivas, ni siquiera cuando estas normas se observan con escrúpulo (cosa que, como hemos podido comprobar en el trabajo de campo, no siempre sucede).

Más allá de los ampliamente reconocidos beneficios económicos que aporta el turismo en el ámbito español, en los últimos años, las aportaciones que desde las ciencias sociales se han venido realizado sobre el fenómeno de la turistificación se han centrado en las consecuencias negativas de los alojamientos turísticos (Gutiérrez, García-Palomares, Romanillos y Salas-Olmedo, 2017) y en los conflictos de convivencia entre residentes y turistas (masificación, desaparición del tejido social, turismo de borrachera...), así como en la banalización y el impacto en la imagen urbana (brandification, estereotipos, la ciudad y el souvenir, etc.). En el primer caso, podemos mencionar las aportaciones de Cabrerizo, Sequera y Bachiller (2016) y Gil y Sequera (2018) para la ciudad de Madrid; Pareja y Simó (2014), Lambea (2017), Elorrieta, Cerdan y Torres-Delgado (2018), Mansilla (2018) y Martín, Martínez, y Fernández (2018) para Barcelona; e Yrigoy (2016) para el caso de Palma de Mallorca. En todas ellas, se pone de manifiesto el impacto negativo de los nuevos agentes turísticos residenciales en la estructura social de los barrios céntricos y la capacidad de contestación social de los movimientos vecinales. En el segundo caso predominan las investigaciones que tienen como objeto de estudio a Barcelona, paradigma de la capacidad reduccionista del turismo para convertir la ciudad y el espacio público en objeto de consumo (Palou, 2009; Yanes, 2009; Benach, 2016).

Sin embargo, ha recibido menor atención científica - que no mediática - el impacto de actividades e instalaciones muy concretas como las terrazas de veladores. En parte porque a pesar de que las asociamos y las clasificamos dentro del ámbito de lo turístico, deberían considerarse en un ámbito más amplio como actividades de ocio y consumo, pues también están dirigidas a la población local. Con todo, merece la pena mencionar las aportaciones de Fernández y Santos (2018), quienes, a partir de un estudio comparativo de las normativas de diferentes ciudades españolas, reconocen las terrazas de veladores como uno de los principales focos de conflicto paisajístico derivado de la actividad turística. También es destacable el estudio encargado por el propio Ayuntamiento de Barcelona a un equipo de investigadoras de la Universidad Politécnica de Cataluña que precisamente realizaba un estudio de caracterización y evaluación de las terrazas en el espacio público de la ciudad, con el fin de emprender una revisión de la fiscalidad que regulaba su implantación. Este estudio reconocía la necesidad de encontrar mecanismos de autocontención de la ocupación del espacio público para hacer compatibles la movilidad de peatones y la actividad de bares y restaurantes (Garcia-Almirall, 2016). El estudio categorizaba las vías urbanas en función de criterios relacionados con el atractivo turístico, el tejido comercial y la intensidad de uso del espacio, además del valor económico atribuible a las terrazas. 


\section{METODOLOGÍA Y ÁMBITOS DE ESTUDIO}

La metodología de esta investigación se basa en una combinación de técnicas cualitativas y cuantitativas. El análisis del marco regulador de las terrazas en Sevilla y Barcelona se ha abordado desde un enfoque netamente cualitativo. Para el caso de Sevilla se ha analizado la normativa vigente aprobada en 2013; mientras que para Barcelona se ha tomado como fuente la ordenanza original de 2014 y no su modificación posterior de 2018, pues en el momento de iniciar la investigación la aprobación de la modificación era muy reciente y se preveía que las terrazas no se habrían adaptado aún al nuevo marco regulador, además de la propia inseguridad jurídica a la que dicha norma está sometida.

El estudio de ambas normativas se ha realizado a partir de la técnica conocida como análisis de contenido, consistente en una lectura científica del texto que reúne las características de ser sistemática, objetiva y replicable (Andréu, 2001). La información se ha completado con la consulta de otros informes institucionales, así como una entrevista en profundidad semiestructurada para cada caso de estudio: concretamente, en Barcelona se ha entrevistado a la Directora del Instituto Municipal de Paisaje Urbano, mientras que en Sevilla la persona entrevistad ha sido una técnica de la Infraestructura de datos Espaciales de la Gerencia de Urbanismo del Ayuntamiento (IDE.Sevilla). En el anexo 1 se incluye la información más relevante obtenida de ambas entrevistas.

Posteriormente se ha analizado la ocupación generada por las terrazas en determinados ámbitos de estudio. Estos ámbitos se han seleccionado en las áreas de mayor incidencia de la actividad turística en Sevilla y Barcelona. Por eso, como paso previo hemos determinado cuáles eran precisamente estos barrios o distritos más turísticos de cada ciudad a partir de diversas variables: los establecimientos hoteleros, los puntos de encuentros de Free Tours y los comercios turísticos especializados (tiendas de souvenirs, bazares...). La mayor densidad espacial de estas actividades económicas en determinados barrios, por lo general céntricos, puede apreciarse en las Figuras 1 y 2, donde dichas variables aparecen cartográficamente representadas. Cabe señalar que este criterio ha sido empleado también en estudios previos para identificar las zonas de mayor presión turística, por ejemplo en el estudio de Garcia-Almirall (2016) para Barcelona. Las bases cartográficas se han obtenido de fuentes municipales (establecimientos hoteleros y comercios) y portales turísticos (Free Tours). Este primer análisis espacial permite discriminar aquellas áreas urbanas menos afectadas por la actividad turística y enfocar el objeto de investigación en las zonas francamente turistificadas. Una vez que se han reconocido estas áreas - se trata de la mitad meridional del casco histórico en Sevilla y del barrio Gótico y su entorno en Barcelona - se ha procedido con la selección de los ámbitos de estudio, esto es, una serie de calles y plazas determinadas, dentro de estos límites.

En las Figuras 3 y 4 se pueden reconocer los ámbitos que finalmente se han seleccionado. Son un total de 11 escenarios urbanos, de diversa morfología, que comprenden desde pequeñas plazuelas (plazas del barrio de Santa Cruz en Sevilla) a grandes ejes viarios abiertos y muy concurridos (Ramblas en Barcelona, Avenida de la Constitución en Sevilla...), donde se pueden apreciar formas de ocupación del espacio público muy diversas. Es en estos ámbitos resultantes donde se ha procedido con una cuantificación detallada de 
la ocupación del espacio público por parte de terrazas de veladores. Para ello el trabajo de campo ha sido una metodología imprescindible. Durante el mismo se ha procedido a recabar datos relativos a ubicación y disposición de las terrazas, número de mesas y sillas, superficie media ocupada por cada módulo y verificación de la información recogida en la licencia de los establecimientos (ver Anexo 2). Finalmente, se ha calculado el Índice de Ocupación (Io), que Praena y García (2018) definen como el espacio ocupado por las terrazas (que llamaremos AT - Área de Terrazas) dividido por el Área Peatonal Útil (APU), tal y como lo expresa la siguiente fórmula:

$$
\mathrm{Io}=\mathrm{AT} / \mathrm{APU}
$$

El AT procede de multiplicar el número de módulos por la superficie media ocupada por cada módulo ${ }^{2}$, mientras que el APU es la superficie de la vía o plaza que resulta de excluir el área correspondiente a calzadas de vehículos y el que ocupa el mobiliario urbano, para lo cual también se ha utilizado la planimetría digital de cada ciudad. En definitiva, el cálculo de este indicador permite conocer el grado de apropiación espacial por terrazas que se hace de la calle o plaza estudiada. La utilidad de este método estriba en que se pone en relación la ocupación particular para el uso privativo con la superficie total de espacio público disponible para el viandante. Es decir, no se pone el acento en el número total de sillas y mesas, sino en si estas se están apropiando de una parte proporcionalmente mayoritaria del espacio público o si, por el contrario, solo ocupan una superficie reducida y, en consecuencia, tolerable.

\footnotetext{
2 Para el cálculo del Área de Terrazas en el caso de Sevilla, también se ha contado con la información geográfica en formato vectorial facilitada por la Infraestructura de Datos Espaciales de Sevilla (IDE. Sevilla), donde se recoge el perímetro de vía pública que cada establecimiento hostelero puede ocupar.
} 
Figura 1

\section{IDENTIFICACIÓN DE LOS BARRIOS MÁS TURISTIFICADOS DE SEVILLA}

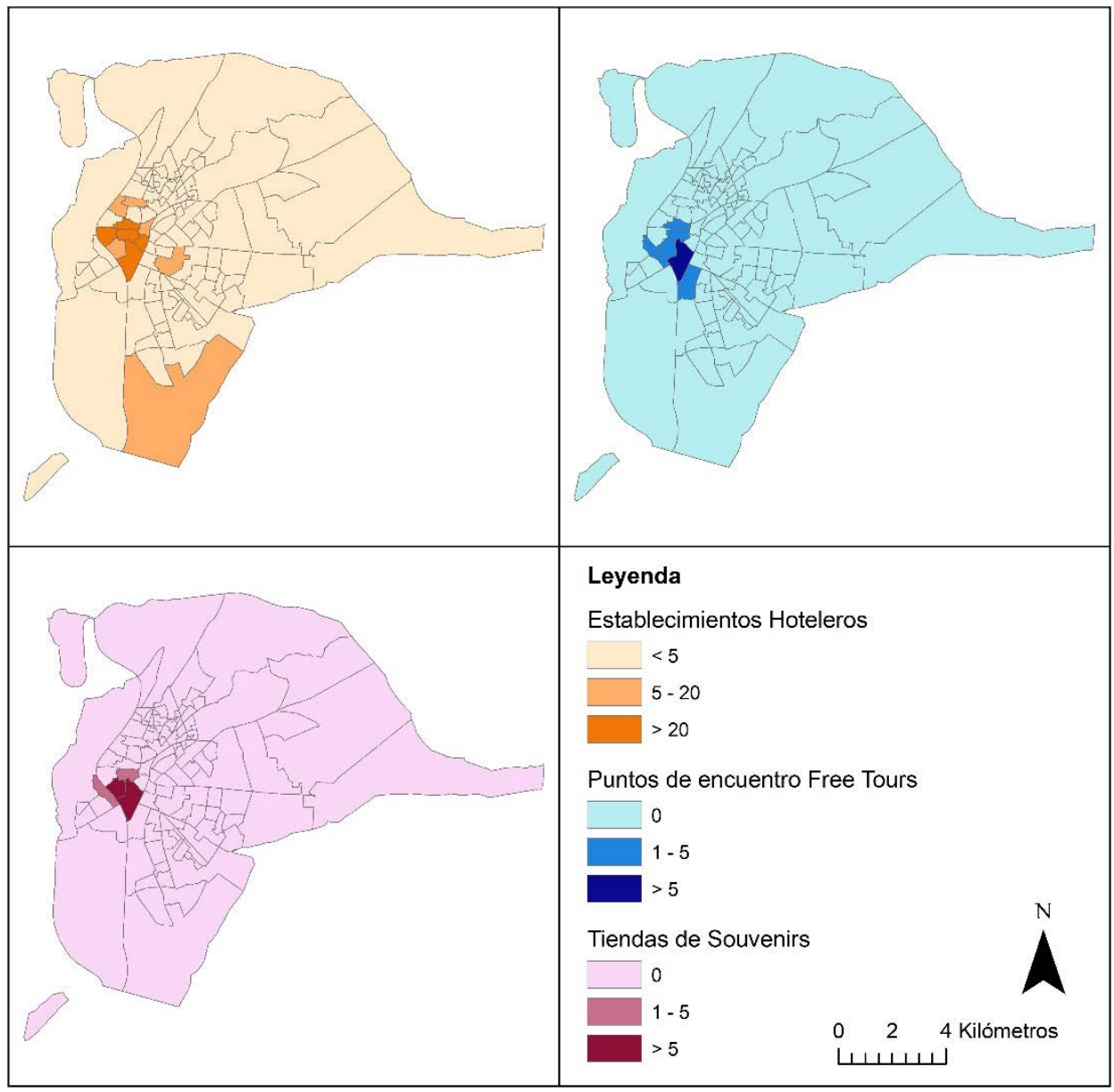

Fuente: Elaboración propia. 
Figura 2

IDENTIFICACIÓN DE LOS BARRIOS MÁS TURISTIFICADOS DE BARCELONA

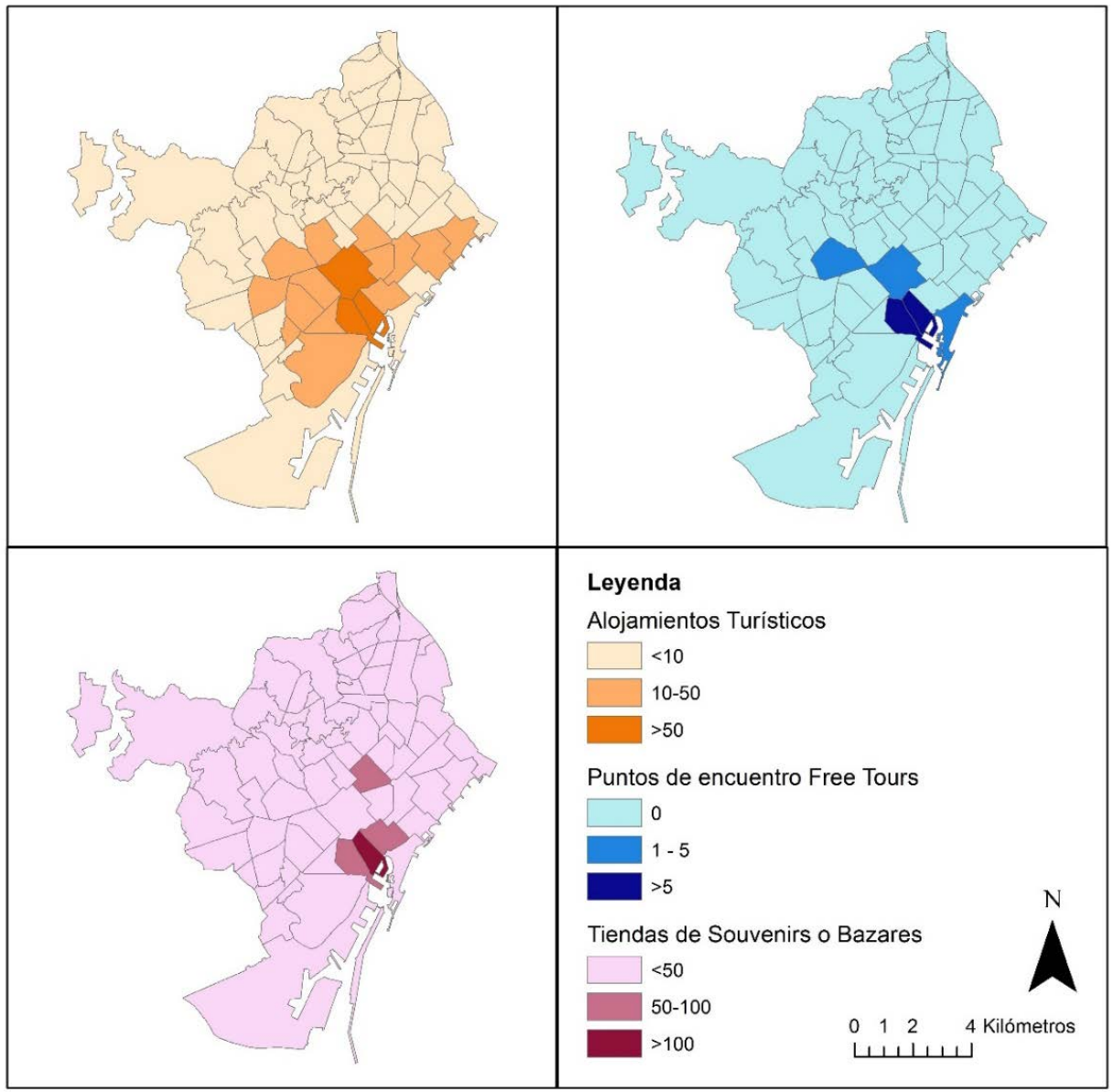

Fuente: Elaboración propia. 
Figura 3

ÁMBITOS DE ESTUDIO DE SEVILLA

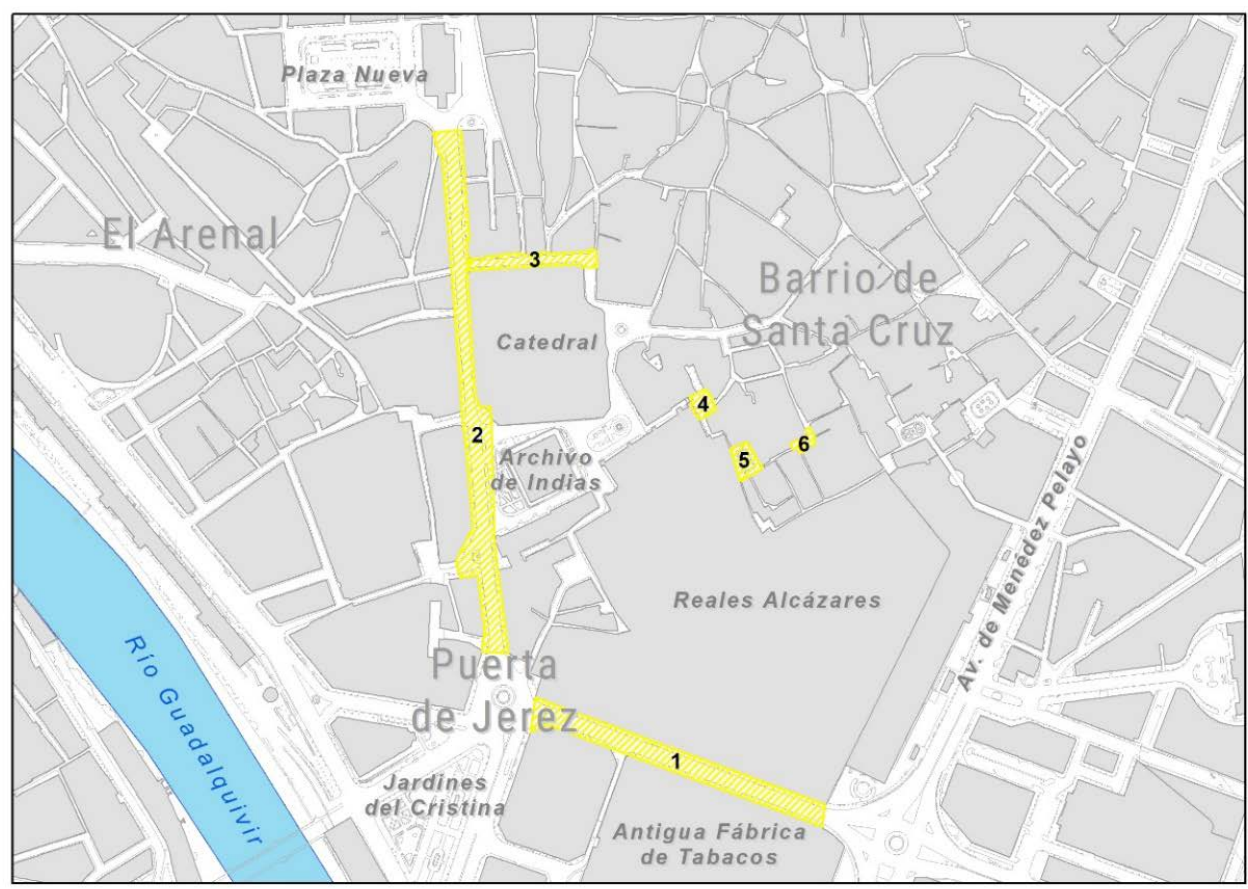

\section{Leyenda}

Casos de estudio

1. Calle San Fernando

2. Avda. de la Constitudión

3. Calle Alemanes

4. Plaza de la Alianza

5. Plaza de Doña Elvira

6. Plaza de los Venerables

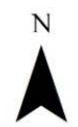

$0 \quad 100$
200 Metros $+$

Fuente: Elaboración propia. 


\section{Figura 4 \\ ÁMBITOS DE ESTUDIO DE BARCELONA}

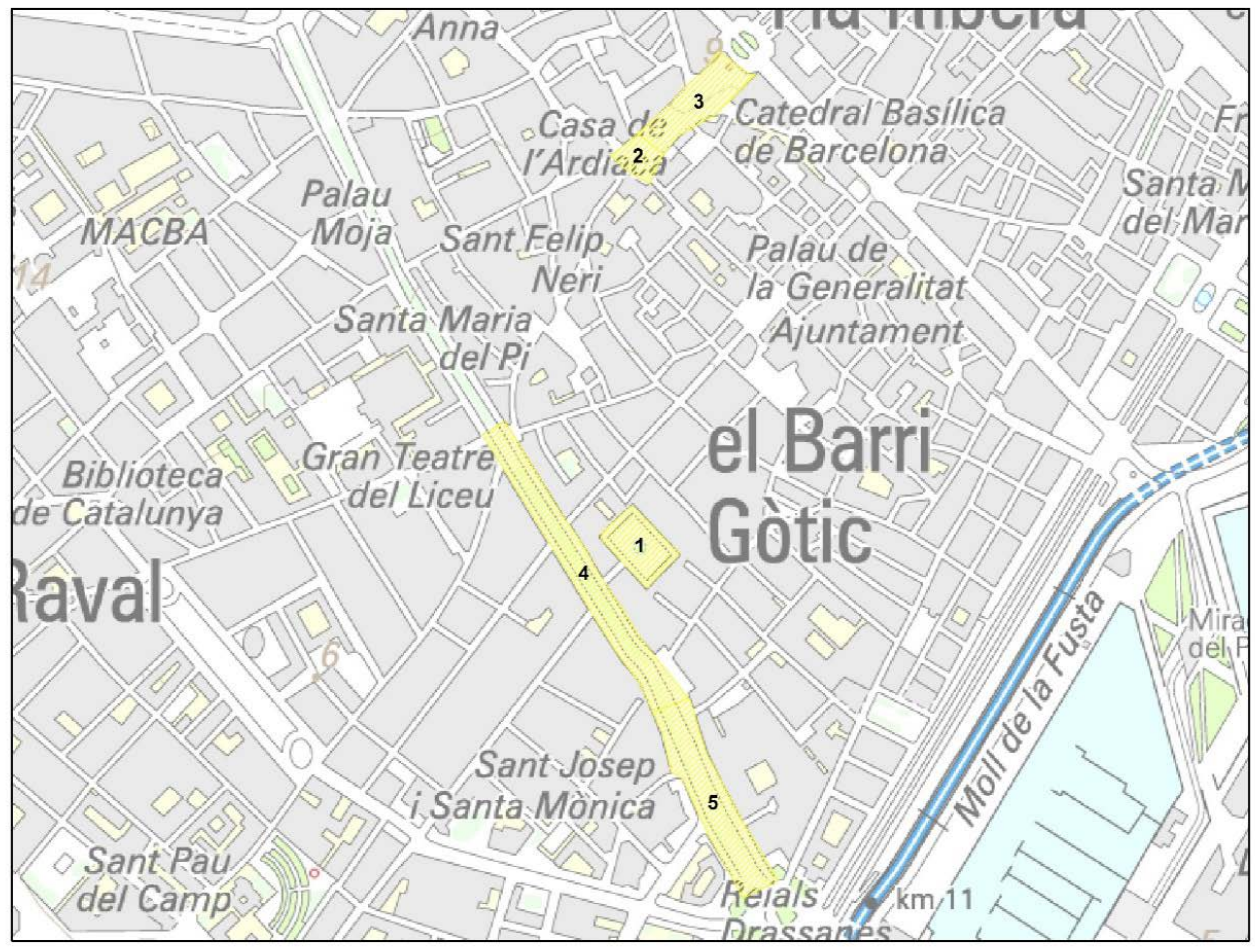

\section{Leyenda}

Casos estudio

1. Plaza Reial

2. Plaza Nova

3. Avenida de la Catedral

4. Las Ramblas: Rambla de los Capuchinos

N

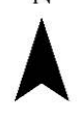

5. Las Ramblas: Rambla de Santa Mónica

Fuente: Elaboración propia. 


\section{EL MARCO REGULADOR DE LA IMPLANTACIÓN DE TERRAZAS}

La normativa analizada en materia de regulación de terrazas de veladores de ambas capitales es relativamente reciente y prácticamente contemporánea. En ambos casos, la necesidad de regulación vino justificada por un gran aumento en la demanda de licencias, en parte por la entrada en vigor de la conocida como ley antitabaco. A esta causa hay que añadir, en el caso de Sevilla, la peatonalización de importantes calles convertidas ahora en ejes comerciales y de ocio. En Barcelona, a su vez, el incremento de la afluencia turística también causó una mayor competencia por el uso del espacio público.

Es en este contexto cuando aparece la polémica sobre las terrazas de veladores, planteando la dificultad de compaginar el derecho al espacio público con la libertad de comercio. Los consistorios reaccionan ordenando los usos y constituyendo nuevos espacios de gobernanza, como comisiones específicas de terrazas donde tienen representación las asociaciones de hosteleros y los colectivos vecinales.

\subsection{Marco regulador en Sevilla}

La normativa vigente en materia de regulación de terrazas de veladores en la capital hispalense fue aprobada en 2013. Viene a sustituir una ordenanza municipal previa de 2009, si bien en la mayoría de los aspectos esenciales, ambos textos son coincidentes, con lo que habría que considerarla como una adaptación menor de la norma precedente. Por tanto, al margen de la incorporación de procedimientos burocráticos que facilitan la concesión de las autorizaciones - con una fórmula rápida denominada "declaración responsable"3 - los parámetros de ocupación de la vía pública se siguen manteniendo.

Por lo tanto, como parte protagonista de la actividad hostelera en la ciudad de Sevilla, se puede decir que la instalación de terrazas de veladores es una práctica que viene estando bajo regulación de alguna u otra forma desde hace bastantes años. Sin embargo, la demanda de nuevas licencias experimentó un incremento significativo a partir del año 2011. A la entrada en vigor de la conocida como ley antitabaco, que favorecía de forma implícita el uso de las zonas exteriores de bares y restaurantes, hay que añadir como causas explicativas de este incremento de licencias la peatonalización de importantes calles como San Jacinto y Asunción, convertidas ahora en los verdaderos ejes comerciales y de ocio de sus respectivos barrios, Triana y Los Remedios. Así, entre 2011 y 2016 el número de licencias para la instalación de veladores se duplica, pasando de $1.051 \mathrm{a}$ 2.093 (Aguilar, 2015; IDE. Sevilla, 2018).

Es en este nuevo escenario de incremento tan significativo de la ocupación del espacio público cuando el asunto de las terrazas de veladores empieza a permear en la opinión pública, conquistando el debate mediático local en torno a la necesidad de compaginar el derecho al espacio público con la libertad de comercio. A ello contribuye además la sensación generalizada de que muchos de los establecimientos hosteleros no cumplen con la normativa, ocupando de manera fraudulenta la vía pública con más

3 La nueva ordenanza se justifica así para adaptarse a la directiva 2006/123 CEE que persigue la simplificación y la eliminación de trabas burocráticas en la prestación de actividades de servicios. 
sillas y mesas de las permitidas, o careciendo de la correspondiente licencia. Sensación que tiene sus fundamentos porque, en efecto, tomando como ejemplo el año 2014, más de un tercio de las inspecciones que realizaron los técnicos municipales desembocaron en un expediente sancionador (Defensor del Pueblo Andaluz, 2016), lo que da buena muestra de la dimensión del conflicto.

Como consecuencia de todo lo anterior, y coincidiendo con el cambio de gobierno que se produce en el ayuntamiento de Sevilla en 2015, a finales de ese mismo año se constituye una Comisión Especial de Terrazas de Veladores, en la que tienen representación la administración municipal, las asociaciones de hosteleros y los colectivos vecinales. En el seno de este organismo consultivo se acuerda la delimitación de áreas necesitadas de una ordenación especial, lugares emblemáticos y céntricos de la ciudad en los que resulta necesario amortiguar el posible impacto negativo de las terrazas de veladores. En consecuencia, se identifican las siguientes áreas "sobre las que resulta primordial realizar un diagnóstico de su situación y regulación actual, para validar después una propuesta consensuada de mejora" (Gerencia de Urbanismo de Sevilla, 2015): Calle Betis, Avenida de la Constitución y Calle San Fernando, Calle Mateos Gago, Calles General Polavieja y Albareda, Plaza de la Alfalfa, Alameda, así como el barrio de Santa Cruz.

Fruto de esta mayor implicación entre agentes públicos y privados, el consistorio ha materializado en los últimos años algunas propuestas significativas de reordenación de las terrazas: por ejemplo, la reducción de un $10 \%$ aproximado de la superficie de terrazas en la Calle San Fernando y la Avenida de la Constitución - muy lejos del 80 \% y $60 \%$ inicialmente propuesto, respectivamente-, así como su total eliminación en el entorno de la Campana (Gerencia de Urbanismo de Sevilla, 2017). El aspecto más llamativo y controvertido de esta nueva política basada en un mayor control lo han protagonizado los agentes de la Policía Local con las batidas de retirada de mobiliario urbano en estas y otras áreas de la ciudad, episodios que la prensa local no ha desaprovechado. No hay que pasar por alto la enorme carga simbólica de estas escenas, en las que los agentes, como brazo ejecutor de los poderes públicos, imponen algo así como la doctrina del derecho a la ciudad, llevándose en un camión de la limpieza aquellos elementos que, por la vía de la invasión, estaban privatizando el espacio colectivo.

Más allá de la propia ordenanza municipal que fija el marco normativo en lo relativo a las terrazas de veladores, existen otras normas de ámbito local que también entran a regular determinadas actividades y usos en estas instalaciones. En concreto, la Ordenanza contra la contaminación acústica, ruidos y vibraciones (2014), en su sección 12a , limita y prohíbe determinadas actividades susceptibles de generar ruido en las terrazas de veladores, tales como cantar, gritar, consumir de pie o incluso jugar al dominó.

\subsection{Marco regulador en Barcelona}

La ordenanza municipal de terrazas que se ha venido aplicando en la ciudad condal en los últimos años data del año 2014, cuando el anterior alcalde, Xavier Trias, aprobó una normativa que afectaría a las 4.500 terrazas de bares y restaurantes que había en aquel momento. Anteriormente no existía una norma específica, sino que la concesión de licencias se basaba 
en algunos artículos de la Ordenanza de Usos del Paisaje Urbano o en las normativas propias de los Distritos, cuya heterogeneidad y dispersión provocaba cierta confusión.

A raíz de la aprobación de la ley antitabaco española en 2011 y del aumento de la afluencia turística, se intensificó el uso del espacio público para actividades turísticas y recreativas. En un contexto general de crisis económica, la demanda de licencias por parte de los restauradores sufrió un aumento considerable, con el fin de responder a una creciente demanda ampliando y mejorando la oferta de servicios de bares y restaurantes. Hasta entonces, las terrazas se habían considerado elementos complementarios y puntuales, tanto desde un punto de vista geográfico (concentradas en determinadas zonas de la ciudad) como temporal (cuyo uso se concentraba en el periodo estival). Sin embargo, a partir de este periodo pasaron a constituir una parte fundamental de los negocios del sector de la restauración, con una enorme proliferación en términos cuantitativos. El resultado fue un aumento de la ocupación del espacio público que generó conflictos a la hora de garantizar la accesibilidad y el uso público de algunos entornos, esencialmente el de circulación y estancia de las personas (Ordenança de terrasses, 2013). Así, el consistorio vio la necesidad de regular específicamente estos elementos de ocupación del espacio público, lo que llevó a la aprobación (el 20 de diciembre de 2013) y posterior entrada en vigor (el 1 de enero de 2014) de la primera ordenanza de terrazas de la historia de la ciudad.

La normativa de 2014 pretendía simplificar la regulación municipal para hacerla más accesible y comprensible, y supuso un paso importante para ordenar el uso del espacio público, aunque su aplicación se preveía de forma no inmediata sino progresiva en los cuatro años posteriores, desde la adaptación a los requerimientos de la licencia hasta la aplicación de las normas de accesibilidad (Ajuntament de Barcelona, 2014). De hecho, unos meses más tarde el Ayuntamiento estimaba que el $56 \%$ de las terrazas de bares y restaurantes incumplía la normativa municipal (Claverol, 2014), y en realidad nunca llegó a aplicarse en su totalidad (N. García, comunicación personal, 1 de octubre de 2018).

Paralelamente, el consistorio emprendió la elaboración y tramitación de una serie de ordenaciones singulares para espacios reducidos de la ciudad (básicamente avenidas y plazas emblemáticas), que requerían una normativa ad hoc que permitiera que las licencias se adaptasen a las características particulares del entorno. La mayor parte de las ordenaciones singulares se centrarían en el distrito de Ciutat Vella, el centro histórico de la ciudad, cuya densa trama urbana contribuye a una mayor competencia por el uso del espacio público. Se trataba de proyectos donde, para establecer la ubicación de las terrazas, se estudiaban múltiples elementos relacionados con el paisaje urbano y la movilidad, como los usos del espacio público en ese entorno, los flujos de peatones, el transporte público o los edificios patrimoniales, entre otros. También se creó, en julio de 2014, la llamada Comisión Técnica de Terrazas, un órgano de naturaleza consultiva, instaurado para evaluar algunos aspectos técnicos previstos en la recién aprobada ordenanza. La Comisión contó, durante algo más de dos años, con la participación de sectores sociales, profesionales y del comercio.

En mayo de 2015, sólo un año y medio después de la entrada en vigor de la ordenanza, se produjo un cambio de gobierno en el Ayuntamiento que provocaría un cuestionamiento del marco regulador y de gobernanza vigentes. El nuevo gobierno puso un 
mayor énfasis en que la elaboración de ordenaciones singulares se realizara mediante procesos participativos sistemáticos y abiertos. Al contrario de lo que podría pensarse, las tensiones entre los distintos actores no remitieron gracias a los espacios de encuentro y participación creados. El Gremio de Restauradores, un agente especialmente activo, no sólo acabó por abandonar la Comisión Técnica de Terrazas (y provocar el consiguiente bloqueo en su funcionamiento), sino que organizó diversas campañas y eventos mediáticos a favor de la preservación de las terrazas de la ciudad y en rechazo a las regulaciones establecidas desde el ayuntamiento, mientras que las entidades vecinales (organizadas en torno a la Federación de Asociaciones de Vecinos de Barcelona y la Asamblea de Barrios por un Turismo Sostenible, entre otros) coordinaban protestas en defensa del uso comunitario del espacio público.

Después de poner en marcha varios procesos participativos que culminaron en más de una veintena de ordenaciones singulares, en verano de 2018 el consistorio sorprendió a la ciudadanía con la aprobación, en el pleno municipal, de un nuevo texto (que se presentó como "modificación" al anterior) que acabó por satisfacer las demandas del sector privado, con el apoyo de la mayoría de partidos políticos representados en el ayuntamiento. Con la entrada en vigor de la ordenanza en 2018, no sólo quedó derogada la norma anterior, sino que también quedarán derogadas todas las ordenaciones singulares en 2020. El nuevo texto ha sido calificado por numerosas entidades vecinales y sociales como "una ordenación del sector público dictada por el sector privado para sus propios intereses" (Ajuntament de Barcelona, 2018), aludiendo al pacto bilateral entre el equipo de gobierno municipal y el Gremio de Restauradores de Barcelona en que se gestó la normativa.

La modificación a la ordenanza de 2014 que se aprobó recientemente se encuentra sometida a una cierta inseguridad jurídica. Por un lado, por encontrarse pendiente de resolución el recurso judicial interpuesto por algunos agentes sociales, y por otro lado, por el carácter ambiguo e impreciso de su articulado, que dificultará su aplicación con criterios homogéneos y objetivos en los diferentes distritos de la ciudad (N. García, comunicación personal, 1 de octubre de 2018). Además, se prevé que la adaptación de las terrazas y del espacio urbano a la nueva regulación sea dilatada y progresiva, por lo que, teniendo en cuenta las fechas en que se realizó el trabajo de campo de la presente investigación, se ha tomado como referencia el texto original que entró en vigor en 2014.

\subsection{Análisis comparado del marco regulador}

A continuación se analiza en detalle, de forma comparada, el contenido de los marcos normativos generales que existen en las ciudades de Sevilla y Barcelona. Para ello, a partir del análisis de contenido de las dos ordenanzas, se ha elaborado el Cuadro 1, que refleja de forma sintética y comparada los principales criterios y determinaciones de regulación de ambas ciudades.

Haciendo una lectura general del anterior Cuadro 1, observamos que las ordenanzas de Sevilla y Barcelona son prácticamente contemporáneas y presentan muchos elementos en común, en la medida en que tratan de regular aspectos similares. No obstante, cabe destacar que la ordenanza de Sevilla es aplicable no sólo a los espacios de uso y dominio público sino también a los espacios de dominio privado a los que pueda acceder el público en general. 


\section{Cuadro 1 \\ MARCO REGULADOR DE TERRAZAS DE SEVILLA Y BARCELONA}

\begin{tabular}{|c|c|c|c|}
\hline & & \\
\hline & & Barcelona & Sevilla \\
\hline \multicolumn{2}{|c|}{ Marco legal general } & Ordenanza de Terrazas & $\begin{array}{l}\text { Ordenanza Reguladora de las } \\
\text { Terrazas de Veladores }\end{array}$ \\
\hline \multicolumn{2}{|c|}{ Entrada en vigor } & 2014 & 2013 \\
\hline \multicolumn{2}{|c|}{ Normativa complementaria } & $\begin{array}{l}\text { Ordenaciones singulares para } \\
\text { espacios determinados }\end{array}$ & $\begin{array}{l}\text { Posibilidad de redacción de } \\
\text { Estudio de Regularización de Usos }\end{array}$ \\
\hline \multicolumn{2}{|c|}{ Ámbito de aplicación } & $\begin{array}{l}\text { Espacios libres de uso } \\
\text { público. }\end{array}$ & $\begin{array}{l}\text { Espacios de uso y dominio público } \\
\text { y espacios libres de dominio } \\
\text { privado a los que pueda acceder el } \\
\text { público en general. }\end{array}$ \\
\hline \multirow{5}{*}{$\begin{array}{l}\text { Principales } \\
\text { regulaciones }\end{array}$} & $\begin{array}{l}\text { Sistema de } \\
\text { delimitación }\end{array}$ & Marca en el pavimento & $\begin{array}{l}\text { Plano (escala 1:200) expuesto a la } \\
\text { vista del público. } \\
\text { No se señala delimitación en el } \\
\text { pavimento. }\end{array}$ \\
\hline & $\begin{array}{l}\text { Tipos de } \\
\text { módulos } \\
\text { previstos }\end{array}$ & $\begin{array}{l}\text { Dos tipos de módulos: módulo } \\
\text { básico (una mesa y cuatro } \\
\text { sillas) y módulo reducido } \\
\text { (excepcionalmente, con una } \\
\text { mesa y dos sillas). }\end{array}$ & $\begin{array}{l}\text { Cuatro tipos de módulos con una } \\
\text { mesa y entre una y cuatro sillas. } \\
\text { Se admiten otros tipos de módulos } \\
\text { por causas dimensionales. }\end{array}$ \\
\hline & $\begin{array}{l}\text { Requisitos } \\
\text { básicos de } \\
\text { localización }\end{array}$ & $\begin{array}{l}\text { Ancho libre de paso mínimo: } \\
1,80 \mathrm{~m} . \\
\text { En los diferentes tipos de vías } \\
\text { y plazas deben dejar al menos } \\
\text { un ancho de paso o superficie } \\
\text { libre del } 50 \%\end{array}$ & $\begin{array}{l}\text { Ancho libre de paso mínimo: } 1,50 \\
\mathrm{~m} . \\
\text { En los diferentes tipos de aceras y } \\
\text { calles peatonales (incluidas de } 4 \mathrm{~m} \\
\text { de ancho o menos) se permite } \\
\text { una ocupación máxima de entre } \\
50-60 \% \text { del ancho. }\end{array}$ \\
\hline & $\begin{array}{l}\text { Regulación } \\
\text { respecto a } \\
\text { elementos } \\
\text { urbanos }\end{array}$ & $\begin{array}{l}\text { Se definen de forma muy } \\
\text { detallada las distancias } \\
\text { mínimas a mobiliario urbano, } \\
\text { arbolado y otros elementos } \\
\text { (alumbrado, señalización, } \\
\text { paradas de bus, etc.). } \\
\text { La distancia mínima a } \\
\text { marquesinas es de } 5 \mathrm{~m}, 1,5 \mathrm{~m} \\
\text { a los elementos de recogida de } \\
\text { residuos. }\end{array}$ & $\begin{array}{l}\text { Se define una distancia mínima de } \\
1,5 \mathrm{~m} \text { a ambos lados de kioscos, } \\
\text { marquesinas de autobuses y } \\
\text { contenedores, fijando una distancia } \\
\text { prudencial (pero inconcreta) a } \\
\text { otros elementos urbanos. }\end{array}$ \\
\hline & $\begin{array}{l}\text { Elementos } \\
\text { de las } \\
\text { terrazas } \\
\text { prohibidos }\end{array}$ & $\begin{array}{l}\text { Elementos acústicos, } \\
\text { audiovisuales, neveras, } \\
\text { iluminación con efectos } \\
\text { de color o intermitencias, } \\
\text { actuaciones en vivo. } \\
\end{array}$ & $\begin{array}{l}\text { No se mencionan elementos } \\
\text { explícitamente prohibidos }\end{array}$ \\
\hline
\end{tabular}




\begin{tabular}{|c|c|c|c|}
\hline & & Barcelona & Sevilla \\
\hline \multirow[t]{3}{*}{$\begin{array}{l}\text { Principales } \\
\text { regulaciones }\end{array}$} & $\begin{array}{l}\text { Tipologías } \\
\text { de espacios } \\
\text { que } \\
\text { requieren } \\
\text { distribución } \\
\text { o } \\
\text { regulación } \\
\text { específica }\end{array}$ & $\begin{array}{l}\text { Son objeto de distribución } \\
\text { previa: plazas, pórticos, } \\
\text { ramblas y paseos, frente } \\
\text { marítimo, playas, puertos, } \\
\text { parques y jardines y chaflanes } \\
\text { con terraza adosada a la } \\
\text { fachada. } \\
\text { Son objeto de ordenación } \\
\text { singular: espacios de interés } \\
\text { de ciudad y espacios de } \\
\text { interés de distrito }\end{array}$ & $\begin{array}{l}\text { El ayuntamiento puede calificar } \\
\text { determinados espacios como: } \\
\text { Espacios físicamente saturados: no } \\
\text { se permite la apertura de nuevas } \\
\text { terrazas } \\
\text { Espacios prohibidos: se restringe } \\
\text { expresamente la instalación }\end{array}$ \\
\hline & $\begin{array}{l}\text { Horarios de } \\
\text { apertura }\end{array}$ & $\begin{array}{l}\text { De domingo a jueves: } 8: 00- \\
\text { 24:00 } \mathrm{h} \\
\text { Viernes y vísperas de festivo: } \\
\text { 8:00 - 1:00 } \mathrm{h}\end{array}$ & $\begin{array}{l}\text { Horario normal: } 6: 00 \text { - 1:00 h } \\
\text { Navidades, Semana Santa, Feria de } \\
\text { Abril, vísperas de festivo y festivo: } \\
\text { 6:00 - 2:00 h }\end{array}$ \\
\hline & \begin{tabular}{|l} 
Almacenaje \\
de \\
elementos \\
de la \\
terraza \\
\end{tabular} & $\begin{array}{l}\text { Deben ser almacenados en el } \\
\text { propio local o en un almacén } \\
\text { anexo }\end{array}$ & $\begin{array}{l}\text { No se permite almacenar o apilar } \\
\text { productos, materiales o residuos en } \\
\text { o junto a las terrazas }\end{array}$ \\
\hline \multicolumn{2}{|c|}{$\begin{array}{l}\text { Sanciones por } \\
\text { incumplimiento }\end{array}$} & $\begin{array}{l}\text { Se prevén infracciones leves, } \\
\text { graves y muy graves (entre } \\
200 \text { y } 900 € \text { ) }\end{array}$ & $\begin{array}{l}\text { Se prevén infracciones leves, } \\
\text { graves y muy graves (entre } 600 \text { y } \\
120.000 € \text { ) }\end{array}$ \\
\hline
\end{tabular}

Fuente: Elaboración propia a partir de Ordenanza Reguladora de las terrazas de veladores (2013) y Ordenança de Terrasses (2013).

En relación a su articulado, la ordenanza de Barcelona es una norma mucho más minuciosa (con sus 91 artículos y varias disposiciones y anexos) que la de Sevilla (40 artículos). La estructura de ambos documentos difiere ligeramente: por un lado, ambos cuentan con algunos capítulos coincidentes, relativos a disposiciones generales, licencias, condiciones de instalación de las terrazas, control e inspecciones, y régimen sancionador. Por otro lado, la ordenanza de Barcelona incluye, además de los ya mencionados, algunos capítulos adicionales relativos a la ordenación singular de terrazas, el régimen fiscal, y la Comisión Técnica de Terrazas.

También se aprecian ciertas diferencias que hacen que la ordenanza de Barcelona sea algo más rígida y menos permisiva, pues detalla en mayor medida los requisitos de localización, distancias mínimas a todo tipo de elementos urbanos (al tiempo que dichas distancias son, en general, mayores), exige una delimitación clara en el pavimento, el ancho libre de paso que han de dejar las terrazas es mayor, requiere ordenaciones singulares o distribuciones previas autorizadas para algunos espacios de la ciudad, se explicitan elementos prohibidos en las terrazas, los horarios son más restrictivos y en general no se prevén excepciones para el incumplimiento de los requisitos. Además, en Barcelona no se otorgan licencias en calles muy estrechas pues incumplirían el ancho mínimo de paso, mientras que en Sevilla se dan indicaciones para calles de menos de $4 \mathrm{~m}$ de ancho. Con 
todo, aparentemente, el poder sancionador de la ordenanza de Sevilla es mayor pues las sanciones previstas para los casos de infracciones son mucho más elevadas.

En definitiva, ambas ordenanzas pretenden establecer una serie de requisitos para la preservación del espacio público y la movilidad de los peatones, si bien la ordenanza de Barcelona es más exigente y precisa en cuanto a los condicionantes para el establecimiento de terrazas, así como en las estipulaciones para garantizar la calidad del paisaje urbano. Destaca el hecho de que ambas ordenanzas establecen unas directrices generales pero explicitan la posibilidad de que algunas áreas concretas de la ciudad se regulen bajo parámetros específicos. En el caso de Barcelona, se prevén ordenaciones singulares para espacios urbanos concretos, como ramblas, calles de plataforma única y plazas, llegando incluso a recoger en sus anexos un listado específico de todos los espacios susceptibles de ordenación singular de la ciudad. En Sevilla, esta circunstancia se contempla por motivaciones distintas, pues se menciona la posibilidad de redacción de un Estudio de Regularización de Usos cuando varios establecimientos soliciten licencia para un mismo espacio libre. Aun así, también se contempla la posibilidad de no otorgar licencias en espacios físicamente saturados, que deben ser declarados a partir de un expediente administrativo. La ordenanza no menciona específicamente los criterios para determinar dicho grado de saturación.

Como podemos apreciar, los criterios que determinan la posibilidad de instalación de terrazas en el espacio público están fundamentalmente relacionados con la proporción de espacio público que ocupan y el ancho libre de paso que deben permitir, de manera que, indirectamente, se impide la instalación de terrazas en espacios demasiado estrechos. Sin embargo, si bien se reserva la posibilidad de limitar más el otorgamiento de licencias en determinadas zonas, ninguna de las dos ordenanzas hace distinciones por barrios, grado de actividad en el espacio público o grado de saturación turística. En otras palabras, se aplican las mismas restricciones a una zona periférica de oficinas donde el espacio público es amplio y tiene poca actividad (donde las terrazas podrían tener un efecto de dinamización y vigilancia social) que a una zona céntrica y turística donde el espacio público es reducido y presenta problemas de masificación. Aun así, presentan la virtud de contener la presión por la ocupación del espacio público y establecer unas reglas claras para los diferentes colectivos afectados, como son los restauradores (a quienes confiere seguridad jurídica), la comunidad usuaria del espacio público y la propia administración.

\section{LA OCUPACIÓN DE ESPACIO PÚBLICO POR LAS TERRAZAS: CASOS DE ESTUDIO}

Atendiendo a los resultados de la identificación de las zonas más turistificadas de ambas ciudades, lo primero que cabe señalar es que las áreas más turísticas de Sevilla y Barcelona coinciden con áreas de alta concentración de terrazas y veladores. El trabajo de campo ha permitido observar la privatización del espacio público por instalación de terrazas, cuantificando para cada calle o plaza el número de locales con terraza, número de mesas y superficie total ocupada por las mismas. Así, se pone de manifiesto que estas calles y plazas no sólo reciben la afluencia y el tránsito de numerosos visitantes en su espacio público, sino que además han perdido parte de éste en favor de un uso privado del sector de la restauración. Este hecho genera una mayor competencia por el espacio público y puede constituir un catalizador de conflictos con la comunidad residente. 
En efecto, en el caso de Barcelona, donde existen encuestas municipales anuales sobre la percepción del turismo por parte de los residentes, se aprecia que el 97,9\% de los habitantes del barrio Gótico (donde se concentran los ámbitos de estudio) considera que vive en un barrio turístico y el 57,5\% quisiera que hubiera menos turistas (Ajuntament de Barcelona, 2017), siendo los porcentajes más elevados de todos los barrios barceloneses. Asimismo, en el caso de Sevilla, el nuevo plan turístico ya reconoce la necesidad de desahogar los ámbitos identificados en esta investigación (Pérez, 2018), que concentran la mayor parte de visitantes.

En el Cuadro 2 se muestra, de forma detallada, la ocupación del espacio público que representan las terrazas en cada ámbito de estudio desde un enfoque cuantitativo, según lo permitido por las propias normativas (es decir, por las licencias de los establecimientos). Tanto en Sevilla como en Barcelona, una mesa con cuatro sillas ocupa alrededor de 3,5 $\mathrm{m}^{2}$; a partir de este dato y la información recabada en el trabajo de campo, así como su tratamiento geoespacial, se ha obtenido el Área de Terrazas y el Índice de Ocupación, que también se representa de forma gráfica en la Figura 5.

\section{Cuadro 2}

CÁLCULO DEL ÍNDICE DE OCUPACIÓN POR VELADORES

\begin{tabular}{|c|c|c|c|c|c|}
\hline Ciudad & $\begin{array}{l}\text { Ámbitos de } \\
\text { estudio }\end{array}$ & $\begin{array}{l}\mathrm{N}^{\circ} \text { de veladores } \\
\text { (mesas/sillas) }\end{array}$ & $\begin{array}{c}\text { AT } \\
\text { (Área de } \\
\text { Terrazas, } \mathrm{m}^{2} \text { ) }\end{array}$ & $\begin{array}{c}\text { APU } \\
\text { (Área Peatonal } \\
\text { Útil, } \mathrm{m}^{2} \text { ) }\end{array}$ & $\begin{array}{l}\text { Io (Índice de } \\
\text { Ocupación) }\end{array}$ \\
\hline \multirow{6}{*}{ Sevilla } & $\begin{array}{l}\text { Calle San } \\
\text { Fernando }\end{array}$ & $\begin{array}{l}93 \text { mesas/ } \\
260 \text { sillas }\end{array}$ & 449,9 & $3.908,4$ & 0,11 \\
\hline & \begin{tabular}{|l|} 
Av. de la \\
Constitución
\end{tabular} & $\begin{array}{l}76 \text { mesas/ } \\
214 \text { sillas }\end{array}$ & 319,8 & $6.450,0$ & 0,05 \\
\hline & Calle Alemanes & $\begin{array}{l}48 \text { mesas/ } \\
162 \text { sillas }\end{array}$ & 125,6 & 981,4 & 0,13 \\
\hline & \begin{tabular}{|l|} 
Plaza de la \\
Alianza \\
\end{tabular} & $\begin{array}{l}38 \text { mesas/ } \\
106 \text { sillas }\end{array}$ & 100,8 & 526,0 & 0,19 \\
\hline & $\begin{array}{l}\text { Plaza de Doña } \\
\text { Elvira }\end{array}$ & $\begin{array}{l}36 \text { mesas/ } \\
144 \text { sillas }\end{array}$ & 129,9 & 744,0 & 0,17 \\
\hline & \begin{tabular}{|l} 
Plaza de los \\
Venerables \\
\end{tabular} & $\begin{array}{c}20 \text { mesas/ } \\
80 \text { sillas }\end{array}$ & 65,4 & 341,0 & 0,19 \\
\hline \multirow{6}{*}{ Barcelona } & Ramblas & $\begin{array}{c}199 \text { mesas/ } \\
739 \text { sillas }\end{array}$ & 685,0 & $17.407,6$ & 0,04 \\
\hline & Capuchinos & $\begin{array}{c}102 \text { mesas/ } 385 \\
\text { sillas }\end{array}$ & 345,5 & $8.182,8$ & 0,04 \\
\hline & Santa Mónica & $\begin{array}{l}97 \text { mesas/ } \\
354 \text { sillas }\end{array}$ & 339,5 & $9.224,7$ & 0,04 \\
\hline & Plaza Real & $\begin{array}{c}554 \text { mesas/ } 1447 \\
\text { sillas }\end{array}$ & 1368,5 & $4.797,7$ & 0,30 \\
\hline & Plaza Nueva & $\begin{array}{l}8 \text { mesas/ } \\
30 \text { sillas }\end{array}$ & 28,0 & $1.501,6$ & 0,02 \\
\hline & \begin{tabular}{|l|} 
Av. de la \\
Catedral
\end{tabular} & $\begin{array}{c}24 \text { mesas/ } \\
94 \text { sillas }\end{array}$ & 84,0 & $6.810,1$ & 0,01 \\
\hline
\end{tabular}

Fuente: Elaboración propia. 
En el caso de Sevilla, el Índice de Ocupación varía sensiblemente entre unas áreas y otras. Se distinguen tres situaciones bien contrastadas. En primer lugar, sobresalen las pequeñas plazas del barrio de Santa Cruz, con Índices de Ocupación próximos al 0,2. Es en estos entornos de tradicional vocación turística donde los veladores tienen más incidencia sobre el espacio público. Al margen de los datos cuantitativos, que ya de por sí son llamativos, la propia contemplación de estos lugares en horas de gran afluencia, con multitud de visitantes, comensales y una apariencia de saturación física, contrasta con la imagen cuando los veladores están recogidos. Solo en este último momento se pueden apreciar los elementos y atributos propios de la morfología urbana de estas plazas. En segundo lugar, las Calles Alemanes y San Fernando presentan similares Índices de Ocupación, en torno al 0,11-0,13, una incidencia de los veladores moderada. Ambas calles coinciden en la distribución totalmente asimétrica de los veladores en uno de los dos márgenes de la calle, ya que si en la Calle Alemanes una de las aceras corresponde enteramente a la Catedral (por tanto no hay comercios), en la Calle San Fernando ocurre lo mismo con el edificio de la antigua Fábrica de Tabacos y el contiguo hotel Alfonso XIII. Eso sí, si bien la Calle Alemanes muestra una distribución más o menos regular de las sillas y mesas a lo largo del acerado, en el caso de la Calle San Fernando la mayor parte de estas se concentran en áreas concretas, provocando una sucesión repetitiva de terrazas casi más propia de un paseo marítimo en una ciudad vacacional mediterránea cualquiera. Por último, la Avenida de la Constitución muestra un Índice de Ocupación más bajo $(0,05)$, como corresponde a una avenida de grandes dimensiones. Sin embargo, también hay que valorar el hecho de que en esta arteria tan importante de la ciudad se hayan tomado medidas específicas de reducción del número de veladores, como también ocurriera en la Calle San Fernando ${ }^{4}$.

Es precisamente en estas dos últimas vías - Calle San Fernando y Avenida de la Constitución - donde las terrazas presentan menores densidades de ocupación. Y es que si se pone en relación el número de sillas (que no deja de ser una medida de la capacidad o aforo máximo de cada terraza) con el Área de Terrazas, se puede obtener el nivel de densidad o de "maximización” del espacio público ocupado. En este sentido, tanto la Calle Alemanes como las plazas del barrio de Santa Cruz muestran unos niveles de densidad mucho más altos: por cada metro cuadrado hay entre 1 y 1,3 sillas, frente a las 0,6-0,7 sillas por metro cuadrado en las anteriores vías. Si bien consideramos mucho más relevante el Índice de Ocupación aquí propuesto - que es el que revela la verdadera medida del impacto de la ocupación del espacio público por parte de terrazas de veladores - , no deja de ser significativo este otro indicador basado en la densidad, puesto que también informa sobre la distinta forma de implantación de estas actividades en función de la fisonomía particular de cada ámbito urbano.

En lo que respecta a Barcelona, lo primero que llama la atención es que los Índices de Ocupación son en general más bajos que en Sevilla. Esto es debido, en gran parte, a la selec-

4 La Comisión Especial de Terrazas de Veladores de Sevilla, órgano en el que están representadas la administración municipal, las asociaciones de hosteleros y los colectivos vecinales, finalmente aprobó la reducción de un $10 \%$ aproximado de la superficie de terrazas en la Calle San Fernando y la Avenida de la Constitución —-muy lejos del $80 \%$ y $60 \%$ inicialmente propuesto, respectivamente-, así como su total eliminación en el entorno de la Campana (Gerencia de Urbanismo de Sevilla, 2017). 
ción de los casos de estudio (vías y plazas amplias con una extensa área peatonal), pues como ya se ha indicado, la ordenanza no permite la ubicación de terrazas en vías muy estrechas.

A pesar de ello, destaca el caso de la Plaza Real, donde el Io es el más alto de todos los ámbitos estudiados $(0,30)$, muy por encima también de los casos de Sevilla. En efecto, esta plaza neoclásica del s. XIX rodeada de pórticos presenta un perímetro completamente saturado de terrazas, donde los usuarios son casi exclusivamente turistas. La Plaza Real no cuenta con una ordenación específica del espacio, a pesar de que la ordenanza general de terrazas la identifica como espacio susceptible de ordenación singular. De hecho, la oficina del distrito realizó los estudios correspondientes para proceder a una regulación singular, aunque posteriormente no llegaron a tramitarse $(\mathrm{N}$. García, comunicación personal, 1 de octubre de 2018). En efecto, éste ha sido uno de los espacios de mayor conflicto entre el ayuntamiento y el Gremio de Restauradores, pues los porches forman parte de la parcela privada de los establecimientos, pero al mismo tiempo constituyen espacios de servidumbre de paso que han sido ocupados por terrazas. A la complejidad de esta plaza se añade, además, una elevada concentración de locales musicales y ciertos privilegios en cuanto a horarios de cierre de las terrazas (más tardío que en el resto de la ciudad), lo que ha provocado importantes afectaciones al descanso de los residentes.

Algo similar ocurre en las Ramblas, también identificada en la Ordenanza de Terrazas como espacio susceptible de ordenación singular, y donde actualmente se está elaborando un Plan Especial de Ordenación. Aunque su Io es más reducido $(0,04)$, se trata de una vía de carácter eminentemente turístico donde el paseo es la actividad favorita de los visitantes, por lo que las terrazas obstaculizan seriamente el tránsito de peatones. Así, el alto número de establecimientos de restauración en esta arteria que separa los barrios del Raval y el Gótico provoca una elevada presencia de terrazas en la plataforma peatonal central, que transforma completamente el paisaje urbano y contribuye a las aglomeraciones de viandantes en los estrechamientos resultantes.

La Plaza Nueva y la Avenida de la Catedral (que son espacios contiguos) presentan los Io más bajos $(0,01-0,02)$, pues se trata de amplios espacios abiertos que contrastan con la trama urbana generalmente estrecha del distrito de Ciutat Vella. Se trata de un área con una gran presencia de actividades culturales y de ocio, así como alta concentración patrimonial (pues no sólo hallamos la catedral de Barcelona, sino también otros edificios con niveles de protección patrimonial de primer orden). Este hecho hace que sea un área muy visitada por los turistas, y si bien existe una importante presencia de terrazas, la distribución de las mismas y el área que proporcionalmente ocupan no provocan una sensación de saturación del espacio. Cabe destacar que este conjunto es el único ámbito estudiado que cuenta con una ordenación singular específica, aprobada en 2017. Dicha ordenación singular tiene en cuenta criterios más complejos y diversos que la ordenanza general para la regulación de las terrazas, como los flujos de viandantes, las actividades y usos que tienen lugar en la plaza,o criterios paisajísticos, entre otros. Así, la ordenación singular establece una serie de regulaciones de distribución, ocupación máxima y distancias mínimas específicas para el ámbito, que difieren de los requisitos y regulaciones más genéricos de la ordenanza de ciudad. 


\section{Figura 5 \\ ÍNDICES DE OCUPACIÓN Y NÚMERO DE VELADORES EN LOS ÁMBITOS DE ESTUDIO}

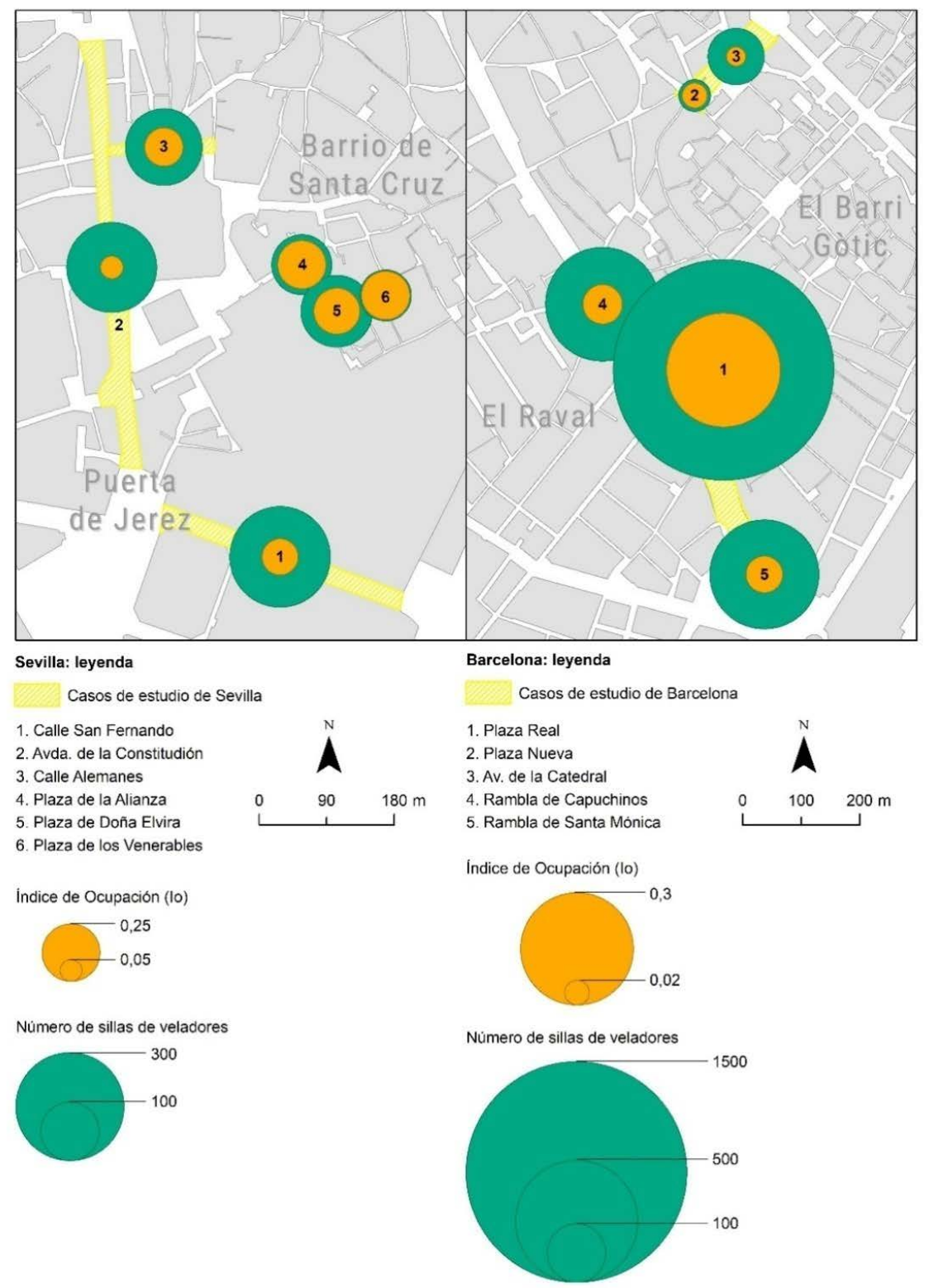

Fuente: Elaboración propia.

Cuadernos de Turismo, 47, (2021), 229-259 
Por lo tanto, resulta significativo que para ambas ciudades se da la circunstancia de que los Índices de Ocupación más bajos coinciden con áreas que se han visto sometidas a una regulación específica. Es decir, la ocupación para uso privativo (lo que de facto supone una privatización del espacio público) presenta menores incidencias solo cuando se legisla más allá de la normativa general. En aquellas plazas y calles sin regulación pormenorizada, el hecho de trasladar las dimensiones recogidas en las condiciones de ocupación genéricas al espacio real no garantiza necesariamente un equilibrio armonizado entre el espacio privativo y el resto del dominio público que queda libre para el viandante. Y es que Índices de Ocupación que rondan el 0,2-0,3 muestran que entre un 20 y un $30 \%$ del Área Peatonal Útil está siendo privatizada por parte de los veladores.

En definitiva, aunque las ordenanzas han servido para ordenar y aportar una mayor seguridad jurídica a la implantación de terrazas, se aprecia que no han tenido un efecto limitador de las mismas. En términos generales, en Barcelona, entre 2015 y 2019 ha habido un incremento de un $37 \%$ en el número de licencias (Cia, 2019), mientras que en Sevilla, entre 2011 y 2016 el número de licencias para la instalación de veladores se ha duplicado, pasando de 1.051 a 2.093 (Aguilar, 2015; IDE. Sevilla, 2018). Específicamente, en los barrios saturados desde el punto de vista turístico de Sevilla y Barcelona, se aprecian índices de ocupación altos, barrios que además presentan, en general, tramas urbanas estrechas con poca proporción de espacio público. Así, el fenómeno de privatización del espacio que supone la instalación de terrazas afecta en especial medida a unos entornos que ya de por sí disponen de poco suelo para el uso comunitario. En el caso de Barcelona, las encuestas municipales de 2017 ya apuntaban la masificación en el espacio público como el principal aspecto negativo del turismo (Ajuntament de Barcelona, 2017), además de otros problemas relacionados con la presencia de terrazas como el ruido o la pérdida de esencia de los barrios.

\section{CONCLUSIONES}

Las ciudades de Sevilla y Barcelona pueden considerarse un ejemplo de cómo el fenómeno del turismo no sólo comporta beneficios económicos a los destinos urbanos, sino que también puede tener efectos indeseados, y convertirse en catalizador de conflictos por el espacio público. La proliferación de veladores en ambas ciudades ha estado fuertemente influenciada por la aprobación de la legislación antitabaco, pero también por el aumento de la demanda de un número creciente de turistas que confluyen en los barrios de mayor atractivo turístico. Este incremento ha contribuido a la transformación de los usos del espacio público, y se han llegado a producir situaciones paradójicas en que se han realizado actuaciones urbanísticas para generar nuevos espacios públicos para la ciudad, que posteriormente han sido rápidamente ocupados por las terrazas que impiden otros usos de los espacios (Síndica de Greuges de Barcelona, 2015).

En un contexto de competencia cada vez más intensa por el uso del espacio, los gobiernos locales han tomado medidas para gestionar el conflicto, tanto de tipo normativo (ordenanzas de terrazas) como de gobernanza (comisiones de terrazas). Sin embargo, los instrumentos de gestión creados a tal efecto no han tenido los resultados previstos, bien por no haber sido implementados completamente, o bien por no haber logrado mitigar el conflicto por el uso del espacio público. 
Las ordenanzas que regulan la implantación de terrazas en las ciudades de Sevilla y Barcelona son prácticamente contemporáneas y presentan grandes similitudes, aunque la ordenanza de Barcelona es más minuciosa, rígida y restrictiva. A pesar de que la aprobación de las ordenanzas ha aportado seguridad jurídica y ha conseguido contener la presión sobre el espacio público en determinados ámbitos urbanos, lo cierto es que no han llegado a ser plenamente implementadas ni han impedido la sobre-proliferación de veladores en los barrios con un espacio público más saturado. Así, ambas ciudades presentan áreas turísticas altamente ocupadas por veladores, como las pequeñas plazas del barrio de Santa Cruz en Sevilla y la Plaza Real en Barcelona, lo que muestra que, tal y como apuntan Fernández y Santos (2018), los conflictos por la saturación y apropiación del espacio público no se deben tanto a la falta de normativa como a la debilidad de los mecanismos de control e inspección por parte de la administración municipal. Pero es que además, el entramado urbano estrecho de los cascos históricos y su paisaje de alto valor patrimonial resultan especialmente vulnerables a esta sobre-ocupación, una cuestión que las ordenanzas generales no tienen en cuenta.

En definitiva, la investigación pone de relieve las limitaciones de la normativa genérica y la necesidad de incluir criterios relacionados con la trama y el paisaje urbano, la actividad del espacio público y el grado de saturación turística a la hora de regular las terrazas en el heterogéneo escenario urbano. De hecho, tanto en Sevilla como en Barcelona existen ordenaciones específicas para algunas zonas que tienen en cuenta criterios complementarios a los meramente relacionados con el ancho de paso, y que han desembocado en Índices de Ocupación más bajos. Sin embargo, esta posibilidad de desarrollar normativas específicas que tengan en cuenta las particularidades de cada espacio no ha sido suficientemente aprovechada por las administraciones locales. El propio Gremio de Restauradores de Barcelona reclamaba, con la implantación de la ordenanza de dicha ciudad, que se tuviera en cuenta la singularidad de los espacios turísticos para aplicar con mayor permisividad la normativa de terrazas (Vila, 2016). Así, coincidimos con el sector privado en que, en efecto, la singularidad de los espacios turísticos debería tenerse en cuenta en la regulación de las terrazas, pero para aplicar criterios específicos más restrictivos que tengan en cuenta la masificación y la incompatibilidad de uso privativo versus comunitario del espacio público, mientras que otros ámbitos de la ciudad con un espacio público poco activo podrían ser dinamizados gracias a la presencia de veladores. Y es que la normativa, como hemos podido comprobar, organiza el espacio público como si fuera una superficie isotrópica, donde cada calle puede ser regulada a partir de un mismo patrón, por el mero hecho de que compartan un mismo estatus demanial. Sin embargo, esta forma tan positivista de ordenar el espacio urbano no encaja bien con las particularidades y singularidades que hacen de los centros históricos de las ciudades mediterráneas, precisamente, lugares de gran interés patrimonial y turístico.

Otro aspecto que merece la pena subrayar guarda relación con la metodología empleada en la investigación y el manejo de una variable derivada como es el Índice de Ocupación. Si bien las licencias otorgadas a los locales de restauración se centran en cuantificar mesas y sillas o la superficie que éstas ocupan, este indicador ha resultado mucho más adecuado para evaluar el impacto de las terrazas sobre el espacio público, pues contempla los veladores en su contexto espacial, es decir, contrasta estos usos con respecto al resto de superficie 
destinada al tránsito peatonal. Resulta ser así una medida del impacto ponderada, ya que no afecta lo mismo una mesa en una gran avenida que en una placita de pequeñas dimensiones, donde su impacto relativo es mayor. Si consideramos esta ocupación como una forma tácita de privatización (no deja de ser una concesión para uso privativo de un bien público), el perjuicio aumenta cuando se rompe este equilibrio entre la compatibilidad de los usos, al concederse un espacio proporcionalmente excesivo a un uso particular que, además, es exclusivamente comercial. Por ello, es importante tomar en consideración no sólo la superficie destinada a actividades de uso privativo sino lo que supone dicha cesión en proporción al espacio público disponible.

Finalmente, no podemos dejar de subrayar el interés de extender el estudio a otros ámbitos de la ciudad y profundizar en la ocupación real por parte de las terrazas en comparación con lo permitido por la licencia, pues algunos establecimientos, en la práctica, exceden lo autorizado por la normativa. Quedaría asimismo por analizar el impacto real de los ingresos que reciben las arcas públicas por el pago de las tasas de ocupación, de manera que se pueda evaluar el balance entre el coste social asociado la pérdida de espacio público y el beneficio económico en forma de impuestos para la administración local.

\section{REFERENCIAS BIBLIOGRÁFICAS}

AGUILAR, C. (2015): «Urbanismo impone más de 700 multas a locales con veladores desde 2011», $A B C$ de Sevilla, 12 de agosto.https://sevilla.abc.es/sevilla/20150812/ sevi-multas-urbanismo-veladores-sevilla-201508112344.html (consulta 22/06/2019).

AJUNTAMENT DE BARCELONA (2014): Ordenança de terrasses de Barcelona. Manual operatiu. Barcelona, Ajuntament de Barcelona.

AJUNTAMENT DE BARCELONA (2017):Percepció del Turisme a Barcelona. Barcelona, Ajuntament de Barcelona.

AJUNTAMENT DE BARCELONA (2018): Modificació de l'ordenança de terrasses. Informe de resultats del procès de participación ciutadana. Barcelona, Ajuntament de Barcelona

ANDRÉU, J. (2001): Las técnicas de análisis de contenido: una revisión actualizada. Documento de trabajo, S2001/03. Sevilla, Centro de Estudios Andaluces.

BELTRÁN VALCÁRCEL, F.F. (2015): «Reflexiones sobre los territorios de la espacialidad turística», Aposta. Revista de Ciencias Sociales, nº 65, pp. 175-185.

BENACH, N. (2016): «¿Ciudades en el mapa o en la guía turística? Venta de la ciudad y sentido del lugar», Revista CIDOB d'Afers Internacionals, $\mathrm{n}^{\circ}$ 113, pp. 89-105.

BENAVIDES, J. (2016): «Sin espacio público no hay ciudad», Hábitat y Sociedad, nº 9, pp. 177-192.

BLANCHAR, C. (2018): «Entitats veïnals i de discapacitats impugnen l'ordenança de terrasses», El País, 4 de diciembre, https:/cat.elpais.com/cat/2018/12/04/catalunya/1543935416_585058.html (consulta: 05/10/2018).

BORJA, J, (2004): Los derechos en la globalización y el derecho a la ciudad. Madrid, Fundación Alternativas.

BORJA, J. (2013):Revolución urbana y derechos ciudadanos. Madrid, Alianza. 
BORJA, J. (2014): «Prólogo», en Espacios públicos, género y diversidad: geografías para unas ciudades inclusivas. Barcelona, Icaria, pp. 5-20.

BORJA, J. y MUXÍ, Z. (2003): El espacio público: ciudad y ciudadanía. Barcelona, Diputació de Bacelona.

CABRERIZO, C. (2016): La ciudad negocio: turismo y movilización social en pugna. Madrid, Cisma.

CABRERIZO, C., SEQUERA, J. y BACHILLER, P.G. (2016): «Entre la turistificación y los espacios de resistencia en el centro de Madrid: Algunas claves para (re)pensar la ciudad turística», Ecología Política, n 52, pp. 78-82.

CAPEL, H. (2010): «Urbanización generalizada, derecho a la ciudad y derecho para la ciudad», Scripta Nova, vol. XIV, no 331 (7), 10 de noviembre de 2018. Disponible enhttp://www.ub.es/geocrit/sn/sn-331/sn-331-7.htm

CIA, B. (2019): «Las terrazas se expanden en plena pugna por el uso del espacio público», El País, 7 de abril. Disponible en: https:/elpais.com/ccaa/2019/04/07/catalunya/1554658344_528120.html (consulta: 21/06/2018

CLAVEROL, C. (2014): «El 56\% de las terrazas de bares y restaurantes de BCN incumplen la normativa municipal», El Periódico, 5 de agosto. Disponible en: https://www. elperiodico.com/es/graficos/barcelona/barcelona-terrazas-normativa-ordenanza-5010/ (consulta: 05/10/2018).

CÓCOLA, A. (2016): Apartamentos turísticos, hoteles y desplazamiento de población. Informe para el debate sobre el nuevo Plan Especial Urbanístico de Regulación de los Alojamientos Turísticos.20 de febrero de 2019. Disponible en www.agustincocolagant.net

COLOMB, C. y NOVY, J. (Eds.) (2016): Protest and resistance in the tourist city. Londres, Routledge.

CONSORCIO TURISMO DE SEVILLA (2018): Informe anual 2017.18 de febrero de 2019. Disponible en https://www.visitasevilla.es/sites/default/files/professionals/files/ Informe\%20anual\%202017.pdf

CORREA, L. (2010): «¿Qué significa tener derecho a la ciudad? La ciudad como lugar y posibilidad de los derechos humanos», Territorios, n $^{\circ} 22$, pp. 125-149.

CORTÉS, J.M. (2010): La ciudad cautiva. Control y vigilancia en el espacio urbano. Madrid, Akal.

DEFENSOR DEL PUEBLO ANDALUZ (2016): Resolución del Defensor del Pueblo Andaluz formulada en la queja 14/4886 dirigida a Ayuntamiento de Sevilla. 22 de junio de 2019. Disponible en http://www.defensordelpuebloandaluz.es/es-necesariocontrolar-caso-por-caso-que-las-terrazas-y-veladores-cumplan-con-la-normativa

EL PERIÓDICO (2017): «Punt final a la 'guerra de les terrasses'», El Periódico, 5 de diciembre, https://www.elperiodico.cat/ca/opinio/20171205/punt-final-a-la-guerra-deles-terrasses-editorial-del-periodico-6476971 (consulta: 05/10/2018).

ELORRIETA, B., CERDAN, A. y TORRES-DELGADO, A. (2018): «Del éxito al conflicto: los impactos sociales del turismo en Barcelona», en I Congreso Internacional Turismo transversal y paisaje. Actas. Málaga, Universidad de Málaga, pp. 578-588.

FERNÁNDEZ, A. y SANTOS E. (2018): «La difícil convivencia entre paisaje urbano y turismo: clasificación de conflictos y propuestas de regulación a partir del análisis 
comparativo de normativas locales», Boletín de la Asociación de Geógrafos Españoles, $\mathrm{n}^{\mathrm{o}} 78$, pp. 180-211.

GARCÍA, A. (2011): La calle a escena. El sistema de espacio público de Sevilla y su entorno metropolitano, retos y posibilidades. Sevilla, Ayuntamiento de Sevilla.

GARCIA-ALMIRALL, M.P. (2016): Estudi de caracterització $i$ avaluació de terrasses en espai públic. Modificació de les ordenances de taxes fiscals de les terrasses. Barcelona, Ajuntament de Barcelona - UPC.

GERENCIA DE URBANISMO DE SEVILLA (2015): La comisión especial de terrazas de veladores acuerda realizar un diagnóstico de las zonas más afectadas para establecer después propuestas consensuadas de mejora. 22 de junio de 2019. Disponible en https://www.urbanismosevilla.org/noticias/la-comision-especial-de-terrazas-de-veladores

GERENCIA DE URBANISMO DE SEVILLA (2017): Acuerdo entre Urbanismo y hosteleros de Constitución y San Fernando para la definitiva distribución de las terrazas de veladores en estos ámbitos. 22 de junio de 2019. Disponible en https://www.urbanismosevilla.org/noticias/acuerdo-entre-urbanismo-y-hosteleros-de-constitucion-y-san-fernando-para-la-definitiva-distribucion-de-las-terrazas-de-veladores-en-estos-ambitos

GIL, J. y SEQUERA, J. (2018): «Expansión de la ciudad turística y nuevas resistencias. El caso de Airbnb en Madrid», Empira Revista de Metodología de Ciencias Sociales, $\mathrm{n}^{\mathrm{o}}$ 41, pp. 15-32.

GLASZE, G.; WEBSTER, C. y FRANTZ, K. (Eds.) (2006): Private cities: global and local perspectives. Nueva York, Routledge.

GUTIÉRREZ, J., GARCÍA-PALOMARES, J.C., ROMANILLOS, G. y SALAS-OLMEDO, M.H. (2017): «The eruption of Airbnb in tourist cities: Comparing spatial patterns of hotels and peer-to-peer accommodation in Barcelona», Tourism Management, vol. 62, pp. 278-291.

IDE. SEVILLA (2018): Infraestructura de Datos Espaciales de Sevilla. Sevilla, Gerencia de Urbanismo-Ayuntamiento de Sevilla.

JOVER, J. y DÍAZ-PARRA, I. (2020): «Gentrification, transnational gentrification and touristification in Seville, Spain», Urban Studies, vol. 57 (15), pp. 3.044-3.059.

JUARISTI, J. (2005): «El aire de la ciudad postmoderna: identidad, espacio público, cultura y miedo», en La ciudad y el miedo (VII Coloquio de Geografía Urbana). Girona, Universitat de Girona, pp. 269-288.

KOHN, M. (2004): Brave New Neighborhoods. The privatization of public space. Nueva York / Londres, Routledge.

LAMBEA, N. (2017): «A policy approach to the impact of tourist dwellings in condominiums and neighbourhoods in Barcelona», Urban Research \& Practice, vol. 10 (1), pp. $120-129$.

LOW, S. (2003): Behind the gates: life, security, and the pursuit of happiness in Fortress America.Nueva York, Routledge.

MANSILLA, J.A. (2018): «Vecinos en peligro de extinción. Turismo urbano, movimientos sociales y exclusión socio espacial en Barcelona», Pasos Revista de Turismo y Patrimonio Cultural, vol. 16 (2), pp. 279-296. 
MARTÍN, J.M.M.; MARTÍNEZ, J.M.G. y FERNÁNDEZ, J.A.S. (2018): «An analysis of the factors behind the citizen's attitude of rejection towards tourism in a context of overtourism and economic dependence on this activity», Sustainability, vol. 10, $\mathrm{n}^{\circ} 8$. 16 de mayo de 2019. Disponible en: https://www.mdpi.com/2071-1050/10/8/2851/htm

MILANO, C. y MANSILLA, J.A. (Eds.) (2018): Ciudad de vacaciones. Conflictos urbanos en espacios turísticos. Barcelona, Pol-len Edicions.

MUÑOZ, F. (2008): Urbanalización: paisajes comunes, lugares globales. Barcelona, Gustavo Gili.

PALOU, S. (2009): «La ciudad fingida. Imágenes y promoción del turismo en Barcelona. Perspectiva histórica y cuestiones del presente», Redmarka: Revista académica de marketing aplicado, $\mathrm{n}^{\mathrm{o}} 3$, pp. 79-104.

PAREJA, M. y SIMÓ, M. (2014): «Dinámicas en el entorno construido: renovación, gentrificación y turismo. El caso de la Barceloneta», Arquitectura, Ciudad y Entorno, vol. 9 (26), pp. 201-222.

PÉREZ, M. (2018): «El nuevo plan del Ayuntamiento busca consolidar el turismo de calidad», EL Correo de Andalucía, 22 de febrero, https://elcorreoweb.es/sevilla/el-nuevoplan-del-ayuntamiento-busca-consolidar-el-turismo-de-calidad-DC3848137 (consulta: 17/10/2019).

PRAENA, G. y GARCÍA, M. (2018): «La privatización del espacio público en las áreas turísticas de Sevilla», en I Congreso Internacional Turismo transversal y paisaje. Actas. Málaga, Universidad de Málaga, pp. 578-588.

RODE, P.; FLOATER, G.; THOMOPOULOS, N.; DOCHERTY, J.; SCHWINGER, P.; MAHENDRA, A. y FANG, W. (2017): «Accessibility in cities: transport and urban form», en Disrupting mobility. Nueva York, Springer, pp. 239-273.

RODRIGUE, J. P. (2017): The Geography of Transport Systems. New York, Routledge

SHELLER, M. y URRY, J. (2000): «The city and the car», International Journal of Urban and Regional Research, vol.24 (4), pp. 737-757.

SÍNDICA DE GREUGES DE BARCELONA (2015): Decisió de la Síndica de Greuges referent a l'actuació d'ofici de referència en matèria de turisme i el seu impacte en la qualitat de vida del veïnat de Barcelona. 22 de abril de 2019. Disponible en: http:// sindicadegreugesbcn.cat/pdf/resolucions/res_131437396314.pdf

SORKIN, M. (Ed.) (2004): Variaciones sobre un parque temático: la nueva ciudad americana y el fin del espacio público. Barcelona, Gustavo Gili

VILA, I. (2016): «Les terrasses de la Rambla i la plaça Reial han de tancar una hora abans des d'avui», El Punt Avui, 30 de julio. http://www.elpuntavui.cat/societat/article/5societat/992185-les-terrasses-de-la-rambla-i-la-placa-reial-han-de-tancar-una-horaabans-des-davui.html (consulta: 21/06/2019).

YANES, S. (2009): «Dialécticas de una calle turística: la Rambla de Barcelona», Ankulegi. Revista de Antropología Social, $\mathrm{n}^{\circ} 13$, pp. 45-54.

YRIGOY, I. (2016): «The impact of Airbnb in the urban arena: towards a tourism-led gentrification? The case-study of Palma old quarter (Mallorca, Spain)» en Turismo y crisis, turismo colaborativo y ecoturismo. XV Coloquio de Geografía del Turismo, el Ocio y la Recreación de la AGE. Palma, Societat d'Història Natural de les Balears, pp. 281-289. 


\section{LEGISLACIÓN}

Ordenança de terrasses (2013). Butlletí Oficial de la Província de Barcelona, Barcelona, 31 de diciembre de 2013.

Ordenanza contra la contaminación acústica, ruidos y vibraciones (2014). Boletín Oficial de la Provincia de Sevilla, 251, Sevilla, 29 de octubre de 2014.

Ordenanza Reguladora de las terrazas de veladores (2013). Boletín Oficial de la Provincia de Sevilla, 106, Sevilla, 10 de mayo de 2013.

\section{ANEXO 1}

\section{RESUMEN DE LAS ENTREVISTAS}

\section{Entrevista a Núria García}

CARGO DE LA ENTREVISTADA: Directora del Institut Municipal de Paisatge Urbà (IMPU)

CASO DE ESTUDIO: Barcelona

LUGAR DE LA ENTREVISTA: IMPU, Av. Drassanes 6-8

FECHA: 1 de octubre de 2018

DURACIÓN DE LA ENTREVISTA: 80 minutos

Hasta el 2013 no había una ordenanza específica de terrazas, sino que existían dos artículos dentro de la Ordenanza de Usos del Paisaje Urbano, al tiempo que algunos distritos tenían su regulación propia.

Pero a raíz de la aprobación de la ley del tabaco, y coincidiendo con el furor del uso (turístico y no turístico) del espacio público, unido al calentamiento global, las terrazas pasaron de ser elementos puntuales, de verano y complementarios a la actividad de los negocios, a ser elementos fundamentales. Además, las tasas que pagan son muy bajas, independientemente de que estén en una zona muy concurrida o poco concurrida.

Cuando la terraza tomó más fuerza las licencias crecieron exponencialmente. Entonces, el consistorio elaboró una ordenanza de terrazas para toda la ciudad, que se aprobó en diciembre de 2013. Esta ordenanza regulaba no sólo los horarios, sino también la ocupación del espacio público y el mobiliario que se puede poner, de forma general. Era una ordenanza que era muy lógica, pero también era rígida, regulaba múltiples parámetros.

El problema es que esta ordenanza, aplicada a Eixample o Ciutat Vella (distritos con una gran presión sobre el espacio público) tenía mucha lógica, pero no para otros distritos con menor presión, o zonas como polígonos, donde el espacio público es muy amplio y tiene poca actividad, y donde seguramente una terraza dinamiza el espacio y contribuye a que haya un cierto control social.

La ordenanza no definía explícitamente un mapa o listado de calles donde no se pueden poner terrazas, pero por aplicación estricta de la norma, hay calles donde no se podían instalar (por ejemplo, porque la acera o la propia calle es muy estrecha y no puede cumplir 
las distancias mínimas a la fachada y el paso de vehículos de emergencia). Esto venía claramente definido en el manual operativo.

Las ordenaciones singulares, a su vez, se fueron elaborando a partir de la aprobación de la ordenanza general de 2013. Son para espacios que no son la acera estándar: una plaza peatonal, una calle de plataforma única semi-peatonal... espacios donde, aplicando los parámetros de la ordenanza, no estaría clara la posible ocupación por terrazas. En estos proyectos de ordenaciones singulares se analizaba cuáles eran los usos de la plaza, la circulación (en caso de que pasaran vehículos), los flujos de peatones, el transporte público, si había alguna feria, los edificios patrimoniales, el arbolado... todos los elementos de paisaje, de movilidad, etc. Era como un proyecto de ocupación del espacio público.

Se aprobaron algunas ordenaciones singulares, pero cuando se contempló aprobar una nueva ordenanza general, se pactó no tramitar más ordenaciones singulares hasta que se tuviera la nueva ordenanza.

El caso de la Plaza Real es muy particular. No hay una ordenación singular de la plaza, lo que existe actualmente en cuanto a terrazas es lo que había históricamente. Ha sido un punto de conflicto, desde el gremio de restauradores se han impugnado varias concesiones de licencias, incluso se llegó a los juzgados con algunos establecimientos. La existencia de los porches es lo que en la práctica delimita las terrazas, aunque en realidad, a pesar de estar dentro de la parcela privada, son espacios de servidumbre, de paso público.

Cuando desde el IMPU se elaboraron las fichas de terrazas siguiendo las determinaciones de la ordenanza general, detectamos que se perdían mesas en algunos establecimientos. Pero hay que tener en cuenta que previamente se había producido un incremente desordenado y desmesurado. Todavía hoy en día, en algunos distritos es común hallar ocupaciones por terrazas que no cumplen lo establecido por la ordenanza. También hallamos situaciones donde es diferente lo otorgado por la licencia y lo que hay puesto en la vía pública, porque ha habido una inspección limitada.

En realidad la ordenanza de terrazas de 2013 no se llegó a aplicar nunca en un $100 \%$. Se ha ido aplicando progresivamente, pero con grandes diferencias entre distritos. Ciertamente era una ordenanza algo rígida, no se adaptaba bien a la singularidad de cada barrio o espacio, y seguramente sí necesitaba una revisión. El problema es que la nueva ordenanza se ha flexibilizado en exceso y presenta problemas desde el punto de vista tanto técnico como jurídico. Así, pone en una situación muy difícil a los técnicos de distrito porque cada uno tendrá que interpretarla a su manera.

El gremio de restauradores ha sido un actor clave en el conflicto por las terrazas. En los procesos participativos hubo un enfrentamiento importante entre el gremio y los representantes vecinales. Finalmente, el gremio hizo una propuesta de redactado de una nueva ordenanza, y consiguió el apoyo de la mayoría de los partidos políticos, de manera que el gobierno local aprobó la nueva propuesta. Para el nuevo texto, desde el IMPU hemos hecho aportaciones de carácter técnico, pero no se han incorporado. Consideramos que presenta ciertas incoherencias desde el punto de vista técnico y jurídico y existen indicios de que contradice la normativa de accesibilidad.

En efecto, existía un consenso a favor de dar más flexibilidad a la aplicación de la norma de 2013, de manera que cada territorio la pudiera adaptar a sus características. Incluso los distritos con más congestión y más terrazas, tenían dificultades para interpretar 
técnicamente aquella ordenanza, porque el redactado era bastante rígido. Sin embargo, la nueva ordenanza es excesivamente flexible: define todos los parámetros como orientativos, se pueden dar por licencia todos los elementos, y no es obligatorio recogerlos durante las horas de cierre. En cambio, los horarios no se han modificado, cuando en realidad son menos restrictivos de lo que exige la normativa de medio ambiente.

Con la nueva ordenanza general, paralelamente, se derogarán las ordenaciones singulares que se han redactado durante los últimos años, en las que se ha trabajado mucho. En algunos espacios incluso se habían encargado estudios de peatones (por ejemplo en Plaza Catalunya), se habían hecho procesos participativos... y todo eso, finalmente, quedará sin validez cuando queden derogadas.

\section{Entrevista a María Victoria Segura}

CARGO DE LA ENTREVISTADA: Técnica de la Infraestructura de datos Espaciales de la Gerencia de Urbanismo del Ayuntamiento de Sevilla (IDE.Sevilla)

CASO DE ESTUDIO: Sevilla

LUGAR DE LA ENTREVISTA: Gerencia de Urbanismo, Avda. Carlos III s/n. Isla de la Cartuja. 41092, Sevilla

FECHA: 10 de julio de 2018

DURACIÓN DE LA ENTREVISTA: 60 minutos

El encuentro mantenido con María Victoria Segura, funcionaria encargada del mantenimiento y explotación de la Infraestructura de Datos Espaciales de la Gerencia de Urbanismo en lo relativo a licencias de terrazas de veladores, tiene como primer objetivo obtener datos espaciales georreferenciados que, si bien son de carácter público, no son de libre acceso (bajo demanda). Sin embargo, el encuentro favorece un intercambio de información y de impresiones muy fructífero, puesto que desde este servicio técnico del Ayuntamiento de Sevilla se nos informa de bastantes procedimientos, pero también inquietudes y valoraciones muy al hilo del controvertido asunto de la regulación de estos usos.

La primera dificultad que nos plantean es que no se ha implantado un método de georreferenciación desde el principio. Las licencias concedidas se acompañan de un plano de situación donde se detalla la ocupación y posición teórica de cada silla y mesa, pero ese plano, a pesar de - o debido a - que está dibujado con todo detalle por arquitectos técnicos sobre la propia planimetría de la gerencia, no incorpora coordenadas XY. Se apunta a la falta de dominio en SIG de estos delineantes, que trabajan por costumbre con información vectorial no georreferenciada.

Para corregir esta limitación, algunos técnicos, como Manolo Ponce, quien también se suma a la reunión en un momento dado, se han dedicado a digitalizar las licencias vigentes hasta 2016 construyendo una geodatabase en ArcGIS. Hasta esa fecha, de las 2093 licencias de terrazas de veladores aprobadas, 1446 ya estaban georreferenciadas. La puesta en marcha de esta herramienta favorecería la consulta de información y facilitaría 
la labor a los inspectores, que hasta entonces solo disponían del GIE (Gestión Integrada de Expedientes), una base de datos que solo permite las consultas expediente por expediente.

Con la información espacial en formato shapefile (.shp) se han podido realizar los cálculos que constituyen el marco metodológico de esta investigación, limitando el trabajo de campo a una función de supervisión.

En cualquier caso, los técnicos nos informan de que una parte de sus esfuerzos se están dedicando a resolver estas limitaciones que condicionan la calidad y la operatividad de la información. Por un lado pensando en las mejoras que supondría en su trabajo cotidiano, visto que Manolo es inspector y tiene que hacer constantes consultas a estas bases de datos de los expedientes. Y por otro lado, pensando en los propios ciudadanos, que podrían disponer de una información pública que garantizaría la trasparencia del funcionamiento de este organismo municipal. Por ello, desde la Gerencia nos informan que sería muy deseable el poder integrar esta información en los visores de geoinformación del ayuntamiento una vez que los registros que componen la base de datos hayan sido revisados, depurados y adecuadamente localizados. 
ANEXO 2

MODELO DE FICHA DE TERRAZA

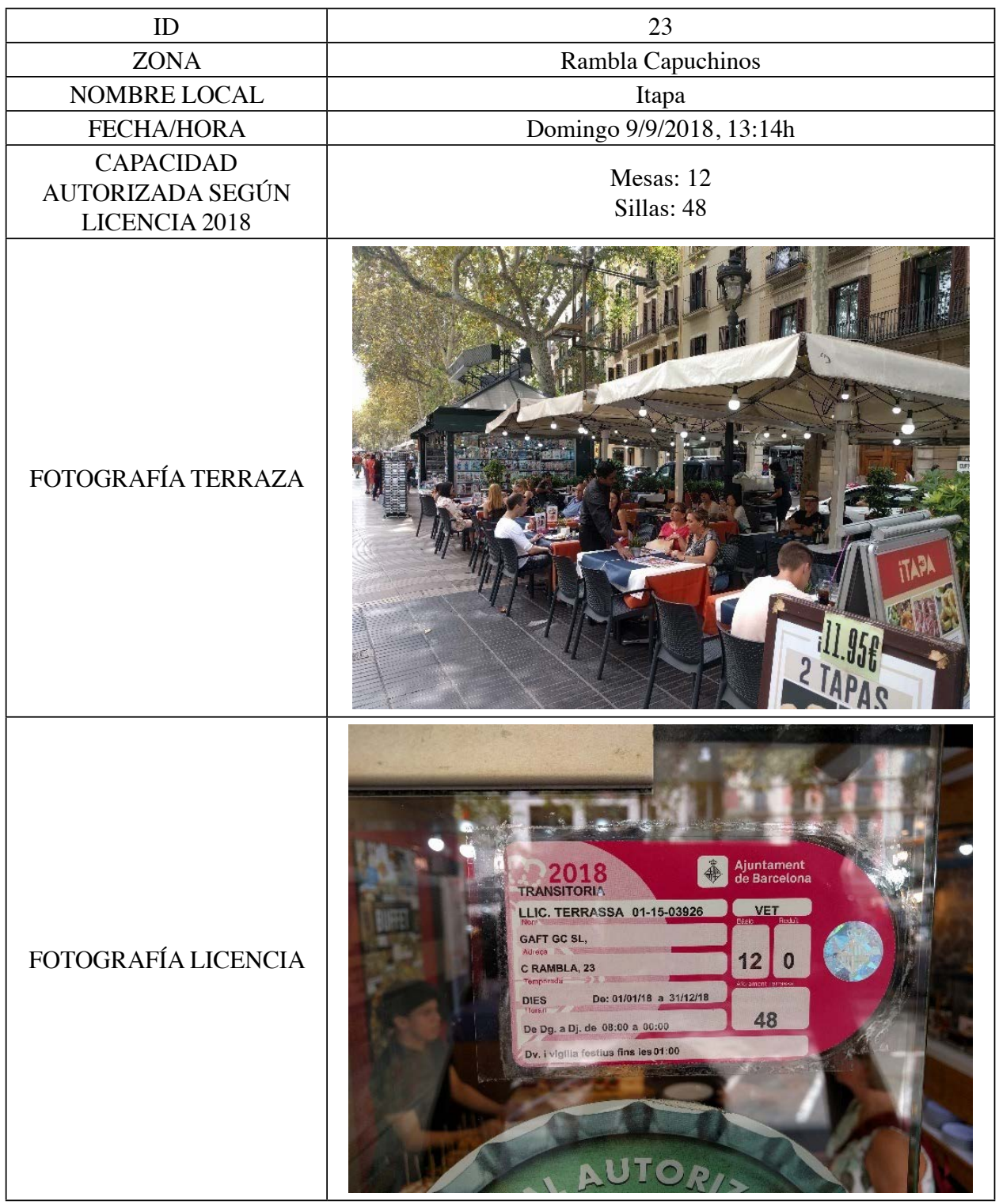

Fuente: Elaboración propia. 